\title{
(4hS) \\ A Generalized Phenomenological Model and Database for the Transport of Water and Current in Polymer Electrolyte Membranes
} 0013-4651/2005/152(8)/A1633/12/\$7.00 () The Electrochemical Society, Inc.

\author{
Sandip Mazumder*,z \\ Department of Mechanical Engineering, The Ohio State University, Columbus, Ohio 43202, USA
}

The semiempirical model developed by Springer et al. [J. Electrochem. Soc., 138, 2334 (1991)] continues to be popular for water transport in polymer membranes. The implementation of this model into a computational fluid dynamic (CFD) code poses some problems. First, the dependent variable in the membrane is the water content, $\lambda$, while that in the diffusion layers and channels is the species mass fractions. Thus, the membrane has to be designated a separate domain, wherein a transport equation for $\lambda$ is solved and iteratively coupled to the mass fractions. This is computationally expensive and sometimes unstable. The second problem is associated with the notion that because the membrane is "thin" it is sufficient to have a few computational nodes across its thickness. A model that extends Springer's model to include convective transport is presented. It is found that accurate calculation of water transport through the membrane requires few hundred nodes. A database that provides water flux and average membrane electrical conductivity for relevant mass-transport Peclet numbers and interfacial conditions is created. When used with CFD calculations, the database will allow accurate and efficient calculation of water and current transport in the membrane without solution of the transport equation for $\lambda$.

(C) 2005 The Electrochemical Society. [DOI: 10.1149/1.1940747] All rights reserved.

Manuscript submitted December 13, 2004; revised manuscript received February 14, 2005. Available electronically July 12 , 2005.

Modeling and simulation, based on computational fluid dynamics (CFD), is now used routinely for analysis, design, and optimization of polymer electrolyte membrane (PEM) fuel cells. ${ }^{1-21}$ The efficacy of such modeling is dependent, in large part, on the accuracy of the submodel that is used to characterize water and current transport through the polymer electrolyte membrane (PEM). Although there have been efforts at modeling both water and current transport through membranes using first-principles microscopic techniques, such as statistical mechanics ${ }^{22,23}$ and molecular dynamics, ${ }^{24,25}$ such models are only meant to enhance fundamental understanding and are difficult to use in the context of large-scale CFD calculations of the entire cell or stack. For this purpose, phenomenological empirical or semiempirical models are more amenable because they can be easily integrated with the continuous equations used in CFD analysis. During the past decade, development of new phenomenological membrane models has been prolific. ${ }^{16,26-38}$ Despite significant effort in this direction, the popularity of the membrane model developed by Springer et al. ${ }^{39}$ for a Nafion membrane continues to surpass any other membrane model, at least when considered in the context of large-scale CFD modeling. The use of the Springer model has been prolific because it characterizes the behavior of a partially hydrated membrane quite reasonably. Recent studies have documented its weaknesses ${ }^{36,40}$ with regard to its inability to accurately describe transport in liquid-equilibrated membranes. Whether this model is the most accurate or appropriate under all circumstances is a separate issue and is not the central focus of this paper. Based on its overwhelming success over the past decade, however, it is clear that this model will continue to be used as long as Nafion membranes are in use.

The implementation of Springer's model in the context of largescale CFD calculations of an entire cell poses two major problems

1. The dependent variable in the membrane is the water content (or hydration index), $\lambda$, while that in the gas-diffusion layers and channels is the species molar or mass fractions. Thus, the membrane has to be designated a separate solution domain, wherein a transport equation for $\lambda$ is solved and iteratively coupled to the mass (or mole) fractions in the remaining regions (Fig. 1). Such iterative coupling is computationally expensive and sometimes unstable.

2. Another common notion within the CFD community is that because the membrane is "thin," it is sufficient to use a few compu-

\footnotetext{
* Electrochemical Society Active Member.

${ }^{\mathrm{z}}$ E-mail: mazumder.2@ osu.edu
}

tational nodes across its thickness. While such a notion may be intuitive, the repercussions of using "few" nodes have never been quantitatively verified.

In this paper, we describe and analyze a generalized phenomenological model for transport of water and current across the membrane, with the specific objective to address the above two issues. The model is built upon the original Springer model but also takes into account convective transport of water across the membrane due to pressure forces. The resulting nonlinear governing equation for water transport is then solved using a conservative finite-volume approach. The numerical errors associated with solution of the governing equation are assessed through systematic grid refinement, and the implications of using "few" nodes are discussed. Ultimately, the numerical results are stored in compact tabular form. The purpose of this database is to readily provide water flux and ohmic loss across the membrane without actually solving for the transport equations within the membrane. Thus, this database, when used within the framework of a CFD code, is expected to result in significant increase in computational efficiency, while at the same time producing accurate results. The motivation for this study, and the ideas presented in this article are, in part, derived from a recent paper by Sui and Djilali. ${ }^{16}$

\section{Mathematical Model and Solution Technique}

Governing equations. - The transport of water in a PEM, in a phenomenological sense, is best described by the following equation derived from continuum mechanics

$$
\frac{\partial C_{\mathrm{w}}}{\partial t}+\nabla \cdot \mathbf{J}_{\mathrm{drag}}+\nabla \cdot \mathbf{J}_{\mathrm{conv}}+\nabla \cdot \mathbf{J}_{\mathrm{diff}}=0
$$

where $C_{\mathrm{w}}$ is the molar concentration of water in the membrane $\left(\mathrm{kmol} / \mathrm{m}^{3}\right) . \mathbf{J}_{\text {drag }}$ is the molar flux $\left(\mathrm{kmol} / \mathrm{m}^{2} / \mathrm{s}\right)$ of water in the membrane due to electro-osmotic drag, $\mathbf{J}_{\text {conv }}$ is the molar flux due to pressure-driven convective transport, and $\mathbf{J}_{\text {diff }}$ is the molar flux due to diffusive transport. Springer et al. ${ }^{39}$ developed semiempirical expressions for the electro-osmotic drag and diffusion fluxes. Rather than use the concentration of water as the primary dependent variable, the so-called water content, denoted by $\lambda$ was used. The water content is a measure of the ratio of the number of water molecules to the number of $\mathrm{SO}_{3}^{-} \mathrm{H}^{+}$charge sites within the membrane. The molar concentration of water, $C_{\mathrm{w}}$, is related to the water content, $\lambda$, by the following relation 


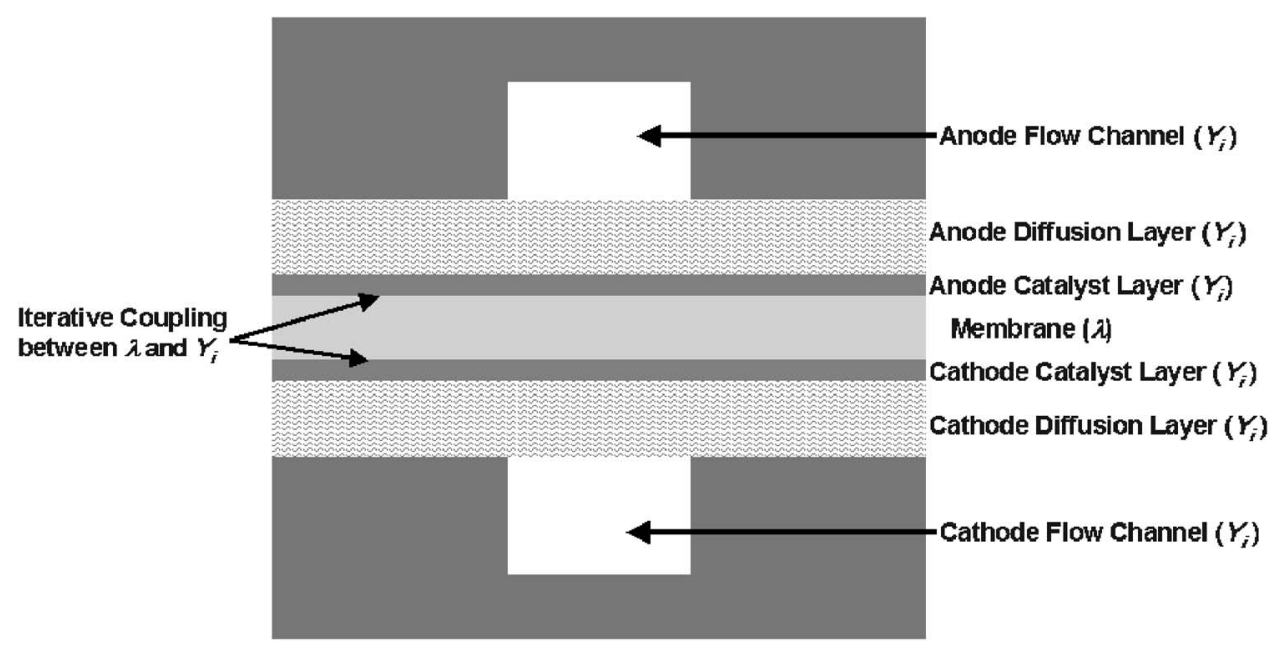

Figure 1. Schematic representation of the cross section of part of a PEM fuel cell showing the various regions and the primary dependent variable that is solved in each of these regions to characterize mass transport.

$$
C_{\mathrm{w}}=\frac{\rho_{\mathrm{m}}^{\mathrm{dry}}}{M_{\mathrm{m}}} \frac{\lambda}{1+s \lambda}
$$

where $\rho_{\mathrm{m}}^{\mathrm{dry}}$ is the density of the membrane $\left(\mathrm{kg} / \mathrm{m}^{3}\right)$ in its dry state, and $M_{\mathrm{m}}$ is the effective molar mass $(\mathrm{kg} / \mathrm{kmol})$ of the membrane. A factor $s=0.0126$ was used to take into account swelling of the membrane. ${ }^{39}$ Although it is stated that this factor was deduced from experimental measurements in dry and fully hydrated Nafion 117 membranes, it is not clear how this number was arrived at, and whether it can be treated as a unique constant

The flux of water due to electro-osmotic drag is written as

$$
\mathbf{J}_{\text {drag }}=\eta_{\mathrm{d}} \frac{\mathbf{i}}{F}
$$

where $\eta_{d}$ is the electro-osmotic drag coefficient that represents the average number of water molecules dragged by each migrating (due to the electric field) proton. The current density vector $\left(\mathrm{A} / \mathrm{m}^{2}\right)$ is denoted by $\mathbf{i}$, and $F$ is the Faraday constant $(\mathrm{C} / \mathrm{kmol})$. Springer et al. $^{39}$ observed that between 2.5 (for almost dry membranes) and 22 (for fully hydrated membranes) water molecules are dragged per proton at a temperature range between 30 and $50^{\circ} \mathrm{C}$. Based on this observation, they proposed a linear expression for the electroosmotic drag coefficient

$$
\eta_{\mathrm{d}}=\frac{2.5}{22} \lambda
$$

The validity of Eq. 4 has been called into question by later researchers. ${ }^{16,26,30,36,38}$ This issue, however, is still a subject of debate, but is not the central focus of the current article. Thus, the current development will retain Springer's original proposition, rather than combining two or more models that may have been developed from completely different sets of data.

The diffusion flux of water is essentially given by the Fick's law, as is written as

$$
\mathbf{J}_{\text {diff }}=-D_{\mathrm{w}} \nabla C_{\mathrm{w}}
$$

where $D_{\mathrm{w}}$ is the diffusion coefficient of water in a Nafion membrane. Once again, following Springer et al., ${ }^{39}$ the diffusion flux may be rewritten in terms of the water content as

$$
\mathbf{J}_{\text {diff }}=-\frac{\rho_{\mathrm{m}}^{\text {dry }}}{M_{\mathrm{m}}} D_{\lambda} \nabla \lambda
$$

where $D_{\lambda}$ is also the diffusion coefficient of water in a Nafion membrane, but now expressed in terms of the water content. Springer et al. ${ }^{39}$ performed extensive measurements to obtain the diffusion coefficient of water as a function of the water content. Their data is best represented by the following piecewise function ${ }^{39}$

$$
\begin{aligned}
& \frac{D_{\lambda}(T, \lambda)}{D_{\mathrm{T}}} \\
& \quad=D_{\lambda}^{\prime} \\
& \quad=\left\{\begin{array}{cl}
1 & \text { for } \lambda \leqslant 2 \\
1+2(\lambda-2) & \text { for } 2<\lambda \leqslant 3 \\
3-1.38(\lambda-3) & \text { for } 3<\lambda \leqslant 4 \\
2.563-0.33 \lambda+0.0264 \lambda^{2}-0.000671 \lambda^{3} & \text { for } \lambda>4
\end{array}\right.
\end{aligned}
$$

where $D_{\mathrm{T}}$ is the temperature-dependent part of the diffusion coefficient, and $D_{\lambda}^{\prime}$ is a dimensionless function that describes the change in the diffusion coefficient with water content. The temperaturedependent part of the diffusion coefficient is available from Springer et $\mathrm{al}^{39}$ and is given by

$$
D_{\mathrm{T}}=10^{-10} \exp \left[2416\left(\frac{1}{303}-\frac{1}{T}\right)\right]
$$

where the unit of $D_{\mathrm{T}}$ is $\mathrm{m}^{2} / \mathrm{s}$, and $T$ is the temperature in Kelvin.

The original model of Springer et al. ${ }^{39}$ did not account for pressure-driven convective transport through the membrane, which is understandable in light of the fact that their measurements were conducted in a cell in which both the anode and cathode were maintained at $3 \mathrm{~atm}$. Whether convective transport in a membrane should be considered or not broaches a topic that is rather nebulous and requires some discussion at this stage. In general, water transport models for the membrane may be classified into two categories: $(i)$ diffusive models ${ }^{28,30,38,39}$ that work well in situations when the membrane is only partially hydrated, i.e., for so-called vaporequilibrated membranes, and (ii) hydraulic models ${ }^{29,41,42}$ that capture some of the physical trends better for fully hydrated membranes, i.e., for so-called liquid-equilibrated membranes. None of these two types of models is able to adequately represent the physics over the full range of operating conditions of a cell. Comprehensive discussion of both types of models may be found in the recent review article by Weber and Newman. ${ }^{40}$ Janssen and Overvelde ${ }^{30,31}$ argued that if the diffusive model is based on concentrated solution theory (i.e., diffusion is driven by the gradient of chemical potential rather than concentration), it does justice to the case when the membrane is liquid-equilibrated. Such an argument is flawed, as pointed out by Weber and Newman, ${ }^{40}$ who clearly delineate the difference between using the dilute solution theory and the concentrated solution theory. Recently, Weber and Newman ${ }^{36}$ have proposed a theory in which it is hypothesized that at low interfacial water activities (i.e., for vapor-equilibrated membranes), the pores within the membrane are essentially collapsed. In other words, there is no continu- 
ous fluid flow passage from one side of the membrane to the other. In such a scenario, the force due to pressure differential between the cathode and anode is essentially balanced by the membrane's mechanical structure, and no convection can occur due to pressure gradient. At high interfacial water activities (i.e., for liquidequilibrated membranes), the pores within the membrane expand significantly, resulting in continuous flow passages through the membrane that transport liquid water by convection. Because this scenario can occur only when the membrane is fully saturated with water, diffusive transport is negligible because there is no concentration gradient to speak of. Thus, as the membrane uptakes water, diffusion continuously decreases while convection increases as the pores expand. It appears that the rate at which convection increases beyond activity of unity is rather sudden, manifesting in what is known as Schroeder's paradox, ${ }^{39,40,43}$ which is characterized by a sudden jump (or discontinuous increase) in water content in the membrane. It is arguable that depending on the interfacial water activities on the two sides of the membrane, one could potentially have all transport processes going on simultaneously within the membrane. Some processes may be dominant over others in certain localized regions of the membrane. Weber and Newman have recently proposed a two-phase model ${ }^{36}$ based on their hypothesis that treats both diffusive and convective transport modes in parallel. The two modes switch in a continuous fashion depending on the fraction of the pores completely occupied by liquid water (i.e., the liquid saturation). Their model appears to capture the entire regime of operation quite well. ${ }^{37}$ Another theory that attempts to explain Schroeder's paradox has been postulated by Choi and Datta. ${ }^{44}$ The implementation of the model presented by Weber and Newman ${ }^{37}$ into a CFD framework would require significant spatial resolution of the membrane in addition to equations for tracking the saturation of liquid water (i.e., a full-blown two-phase description of transport). Moreover, all properties become transport mechanism dependent and need to be refitted. Thus, although the model by Weber and Newman appears to be the best model available to date for mimicking Schroeder's paradox and bridging between the two extreme modes of operation, for this study, we assume that convective transport occurs through the membrane irrespective of the interfacial concentrations at the membrane surfaces, as has been assumed by several other past studies. ${ }^{34,45,46}$

Thus, following this assumption, the convective molar flux of water through the membrane is given by

$$
\mathbf{J}_{\text {conv }}=\mathbf{U} C_{\mathrm{w}}
$$

where $\mathbf{U}$ is the bulk fluid velocity vector. In the limiting case of $\lambda=22$ everywhere, the convective flux, according to this model, is very high, while diffusive transport is zero. Thus, the model does posses some elements of the theory proposed by Weber and Newman. ${ }^{33}$

Substituting Eqs. 2-4, 6, and 9 into Eq. 1 yields

$$
\begin{gathered}
\frac{\partial}{\partial t}\left[\frac{\rho_{\mathrm{m}}}{M_{\mathrm{m}}} \lambda\right]+\nabla \cdot\left[\frac{2.5}{22} \frac{\mathbf{i}}{F} \lambda\right]+\nabla \cdot\left[\frac{\rho_{\mathrm{m}}}{M_{\mathrm{m}}} \mathbf{U} \lambda\right] \\
-\nabla \cdot\left[\frac{\rho_{\mathrm{m}}}{M_{\mathrm{m}}} D_{\lambda} \nabla \lambda\right]=0
\end{gathered}
$$

where the new notation $\rho_{\mathrm{m}}=\rho_{\mathrm{m}}^{\mathrm{dry}} /(1+s \lambda)$ has been used. For further developments, we restrict ourselves to steady state and a value of $s$ equal to zero, such that $\rho_{\mathrm{m}} \approx \rho_{\mathrm{m}}^{\mathrm{dry}}$. The assumption of $s=0$ is made for two reasons. First, as discussed earlier, the value proposed in Springer's original paper is not clearly explained. Second, as becomes clear later, a value of $s=0$, allows creation of a compact database in terms of nondimensional parameters that is otherwise not possible. Equation 10 can be solved numerically no matter what value of $s$ is chosen, and therefore, the value of $s=0$ is chosen only to facilitate creation of a compact database, which is one of the main objectives of the current endeavor. Under the afore-stated two assumptions, Eq. 10 may be rewritten as

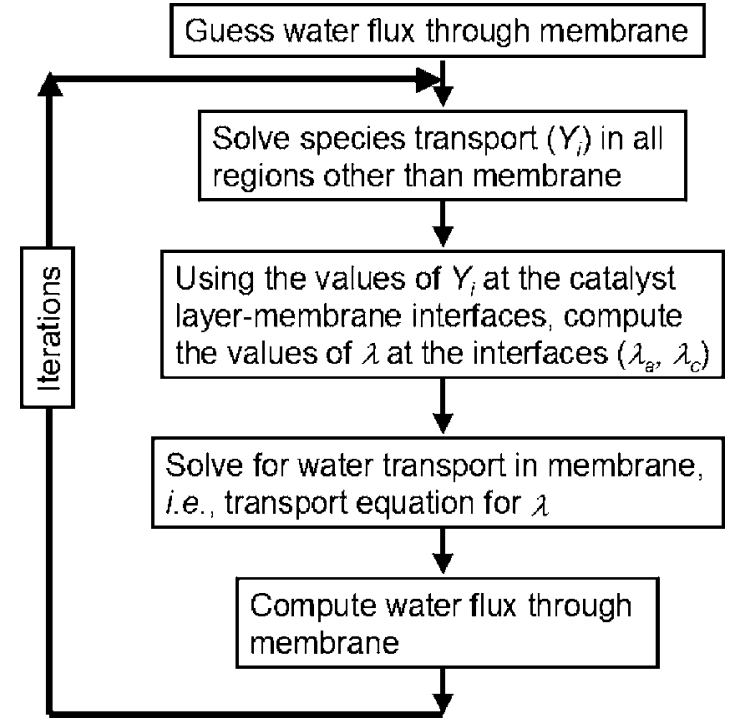

Figure 2. Procedure for coupling the solution in the membrane with the rest of the fuel cell for full-scale PEMFC calculations.

$$
\left(\mathbf{U}_{\mathrm{d}}+\mathbf{U}\right) \cdot \nabla \lambda=\nabla \cdot\left(D_{\lambda} \nabla \lambda\right)
$$

where $\mathbf{U}_{\mathrm{d}}$ is the drag (or drift) velocity $(\mathrm{m} / \mathrm{s})$ and is expressed as

$$
\mathbf{U}_{\mathrm{d}}=\frac{2.5}{22} \frac{\mathbf{i}}{F} \frac{M_{\mathrm{m}}}{\rho_{\mathrm{m}}}
$$

In arriving at Eq. 11 from Eq. 10, the fact that both $\mathbf{U}_{\mathrm{d}}$ and $\mathbf{U}$ are constants is used. Equation 11 represents the steady-state convection-drift-diffusion equation encountered in classical transport theory.

Because the membrane is considerably thinner than either the spacing between channels or the channel length, the gradient of water concentration perpendicular to the membrane is significantly larger than the gradients in the in-plane directions. Furthermore, the components of the current density in the in-plane directions are significantly smaller than the component in the through-plane direction. The problem, thus, reduces to a one-dimensional problem governed by the following second-order ordinary differential equation, where $x$ is the coordinate in the through-plane direction

$$
\left(u_{\mathrm{d}}+u\right) \frac{d \lambda}{d x}=\frac{d}{d x}\left(D_{\lambda} \frac{d \lambda}{d x}\right)
$$

In Eq. 13, $u_{\mathrm{d}}$ is the component of the velocity due to electro-osmotic drag perpendicular to the membrane and is obtained using Eq. 12. The current density vector is substituted by its component in the direction perpendicular to the membrane, i.e., $i_{x} . u$ is the component of the convective velocity perpendicular to the membrane and is best estimated using Darcy's law

$$
u=-\frac{\kappa}{\mu} \frac{d p}{d x} \approx-\frac{\kappa}{\mu} \frac{p_{\mathrm{c}}-p_{\mathrm{a}}}{L}
$$

where $p_{\mathrm{c}}$ and $p_{\mathrm{a}}$ are pressures at the membrane surface on the cathode and anode sides, respectively. Equation 13 needs to be solved to determine the net flux of water across the membrane.

Boundary conditions. - Determination of the appropriate boundary conditions for Eq. 13 requires examination and discussion of the context in which this equation is to be used. Figure 2 depicts an algorithm that is generally used to iteratively couple ${ }^{39}$ Springer's model in the membrane to the rest of the solution domain. It is clear that the boundary conditions for Eq. 13 are Dirichlet boundary conditions, with prescribed values $\lambda_{\mathrm{a}}$ and $\lambda_{\mathrm{c}}$. Because the objective of this paper is to create a database by solving Eq. 13 off-line, careful 
consideration must be given to the range of values that $\lambda_{\mathrm{a}}$ and $\lambda_{\mathrm{c}}$ may attain. The contention is that both $\lambda_{a}$ and $\lambda_{c}$ may attain any value between 0 and 22 independently, for the following reasons:

1. The relative humidity of the anode and cathode inlet streams are independent parameters that may assume any value between 0 and $100 \%$.

2. The interfacial (at membrane-catalyst layer interface) concentrations of water vary spatially in the direction tangential to the membrane surface and are dictated by a large number of factors, such as geometry, operating conditions, and material properties. Thus, any combination of $\left[\lambda_{\mathrm{a}}, \lambda_{\mathrm{c}}\right]$ is conceivable at a given spatial location on the membrane.

3. During the process of iteration, the pair of values on the two sides of the interface, i.e., $\left[\lambda_{\mathrm{a}}, \lambda_{\mathrm{c}}\right]$, may change arbitrarily and may attain any possible value. Based on the above possible scenarios, it is fair to conclude that if Eq. 13 is solved off-line and the results tabulated, then these tabulations should span all possible combinations of $\left[\lambda_{\mathrm{a}}, \lambda_{\mathrm{c}}\right]$ with their values varying independently between 0 and 22. The model proposed by Springer et al. ${ }^{39}$ is valid only for $\lambda<16.8$, i.e., in the region where the water content varies smoothly with activity. Here, the model has been extrapolated up to $\lambda=22$, and the user of the database has the choice of either using this extrapolated data with the understanding that this is not valid in a strict scientific sense, or disregarding this part of the table.

Numerical solution.- Analytical solution to Eq. 13 is possible if the diffusion coefficient is a constant. In this particular case, where the diffusion coefficient is a function of $\lambda$ itself, Eq. 13 is essentially nonlinear and cannot be solved analytically. Furthermore, because $D_{\lambda}$ is a piecewise function, it is not differentiable. Thus, any numerical method that attempts to solve Eq. 13 in its original differential form (such as finite-difference methods) will be fundamentally flawed and is likely to result in stability problems during convergence or in physically meaningless solutions. The correct and robust method for solving Eq. 13 is to use its equivalent integral form, i.e., the so-called finite-volume method. ${ }^{47}$ Finite-volume methods encounter no difficulties because although $D_{\lambda}$ is not differentiable, it is still continuous. Although Springer et al. ${ }^{39}$ did not explicitly use the terminology "finite-volume" in their original paper, it is clear upon careful reading of their paper that they did indeed use the integral form of the governing equations in their final iterative solution procedure.

In this work, the finite-volume method was used to solve Eq. 13. The diffusion term was treated using a second-order central differencing scheme, while the drift and convection terms were treated using a first-order upwind differencing scheme. The choice of these discretization schemes was prompted by the fact that they are the schemes of choice in most commercial CFD codes and not necessarily because they are the most accurate. As mentioned earlier, it is common practice within the CFD community to use "few" nodes within the membrane. By using the same discretization schemes as used in commercial CFD codes, we can quantify the numerical errors being made by using "few" nodes in large-scale CFD calculations using commercial CFD codes.

Current transport.-For full-scale fuel cell calculations, one other quantity of interest is the ohmic loss (or drop in membrane phase potential) across the membrane. If the solution for the membrane region is computed off-line and tabulated, one must have the ohmic loss readily available in order to compute the polarization of the cell. The conservation of current in the membrane gives

$$
\nabla \cdot \mathbf{i}=0
$$

Using Ohm's law, assuming one-dimensional current transport, we have

$$
\frac{d i_{x}}{d x}=\frac{d}{d x}\left(-\sigma_{\mathrm{m}} \frac{d \phi_{\mathrm{m}}}{d x}\right)=0
$$

where $\sigma_{\mathrm{m}}$ is the ionic conductivity of the membrane (loosely referred to as the electrical conductivity of the membrane), and is obtained directly from Springer et al. ${ }^{39} \phi_{\mathrm{m}}$ is the membrane phase electric potential. Integration of Eq. 16 twice yields

$$
\phi_{\mathrm{ma}}-\phi_{\mathrm{mc}}=i_{x} \int_{0}^{\mathrm{L}} \frac{d x}{\sigma_{\mathrm{m}}}
$$

where $\phi_{\mathrm{ma}}-\phi_{\mathrm{mc}}$ is the drop in membrane phase potential across the membrane. In order to evaluate this drop, it will be necessary to compute the right side of Eq. 17 numerically after the distribution of $\lambda$ within the membrane has been computed. For off-line calculations, this would necessitate storage of the distributions of $\lambda$, which is impractical. To circumvent the problem, we define an average membrane conductivity, $\left\langle\sigma_{\mathrm{m}}\right\rangle$, that produces the same potential drop across the membrane for a prescribed current density, i.e.

$$
\phi_{\mathrm{ma}}-\phi_{\mathrm{mc}}=i_{x} \int_{0}^{\mathrm{L}} \frac{d x}{\sigma_{\mathrm{m}}}=i_{x} \frac{L}{\left\langle\sigma_{\mathrm{m}}\right\rangle}
$$

yielding

$$
\left\langle\sigma_{\mathrm{m}}\right\rangle=L / \int_{0}^{\mathrm{L}} \frac{d x}{\sigma_{\mathrm{m}}}
$$

Equation 19 allows tabulation of a single value for the average ionic conductivity for each prescribed $\left[\lambda_{\mathrm{a}}, \lambda_{\mathrm{c}}\right]$ pair, rather than a distribution.

\section{Results and Discussion}

As mentioned earlier, this paper has two main objectives. The first objective is to quantify the numerical errors associated with finite-volume-based numerical solution of the governing 1D equation of water transport across the membrane. The second objective is to develop a database that readily provides water flux and ohmic loss across the membrane for CFD calculations of a fuel cell or stack.

Numerical errors and accuracy.-Equation 13 was solved using the finite-volume method, discussed earlier. The mesh (uniform, in this case) was refined systematically by doubling the number of cells. In each case, iterations were continued until the residual (defined, in this work, as the 12 norm of the discretized equations) reduced below $10^{-10}$. Figure 3 shows the spatial profiles of $\lambda$ as a function of mesh density for two arbitrarily chosen $\left[\lambda_{\mathrm{a}}, \lambda_{\mathrm{c}}\right]$ pairs. These calculations were performed for a baseline value of $i_{x}$ $=0.5 \mathrm{~A} / \mathrm{cm}^{2}, T=30^{\circ} \mathrm{C}$, and $p_{\mathrm{c}}-p_{\mathrm{a}}=2$ bars.

It is clear from Fig. 3 that the number of cells used across the membrane plays a crucial role in the accuracy of the numerical solution. For the two cases shown here, the solution becomes grid independent only when more than 100 cells are used. Of engineering interest is the error incurred in computing the flux of water using a coarse grid (see Table I). Two important issues are highlighted by the data shown in Table I. First, the numerical errors, associated with the use of just five computational cells across the membrane, are strongly dependent on the boundary conditions used and can be greater than $100 \%$. Second, for cases where the diffusion flux opposes the flux due to electro-osmotic drag (resulting in a low net flux), the errors can be very large. In fact, because the slope of $\lambda$ changes significantly with grid resolution (Fig. 3), using a coarse grid for such situations may alter the direction of water flow, as indicated for the $\left[\lambda_{\mathrm{a}}, \lambda_{\mathrm{c}}\right]=[4,14]$ case with five cells. Clearly this can lead to significantly erroneous results in the overall calculation of the cell and is unacceptable.

The sensitivity of the numerical solution to the mesh is best understood by examining the functional nature of the solution to Eq. 

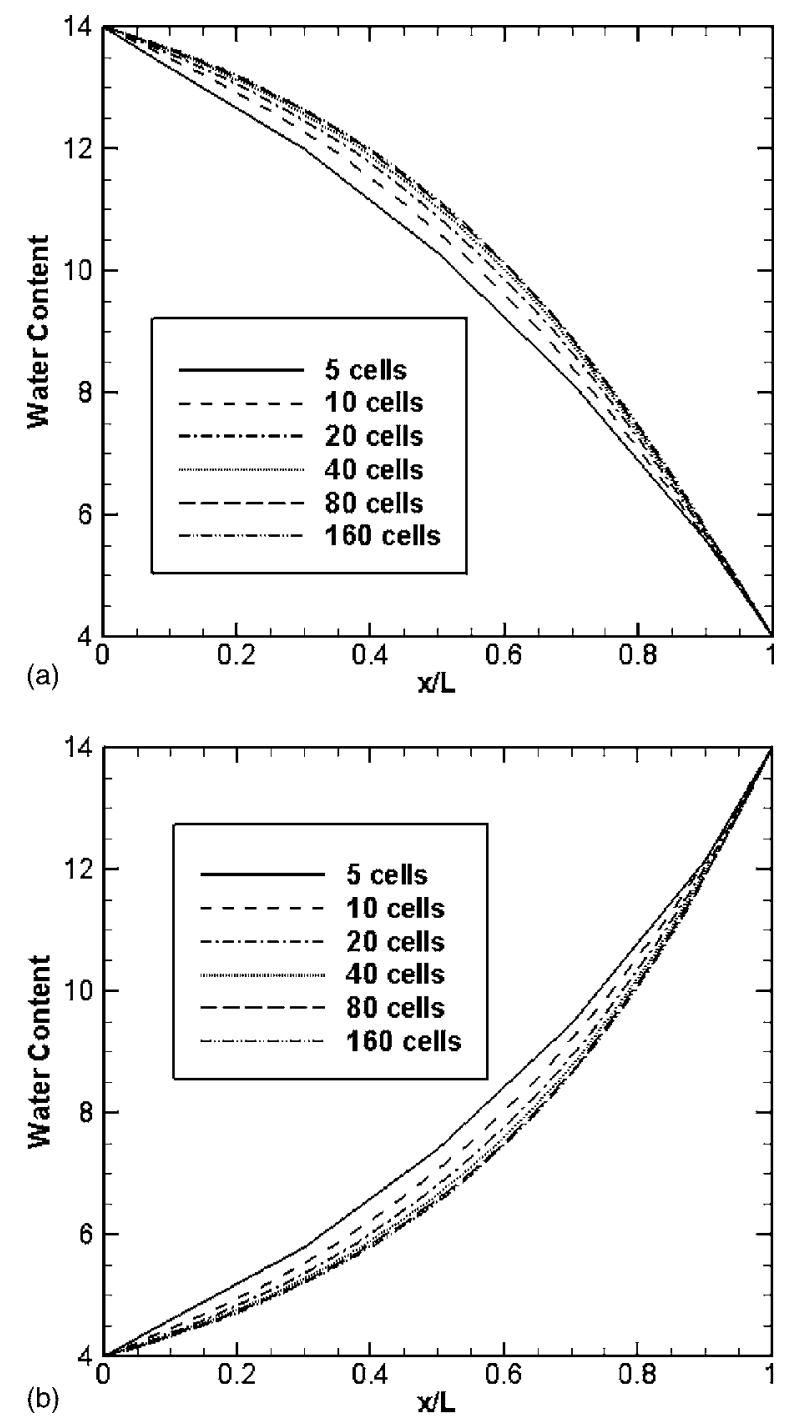

Figure 3. Water content spatial profiles for two cases as a function of mesh density. (a) $\left[\lambda_{\mathrm{a}}, \lambda_{\mathrm{c}}\right]=[14,4]$; and (b) $\left[\lambda_{\mathrm{a}}, \lambda_{\mathrm{c}}\right]=[4,14]$.

13 for the case when the diffusion coefficient is constant $(=D)$. As mentioned earlier, Eq. 13 can then be solved analytically, and the analytical solution is

$$
\lambda(x)=\lambda_{\mathrm{a}}+\left(\lambda_{\mathrm{c}}-\lambda_{\mathrm{a}}\right) \frac{\exp (\alpha x)-1}{\exp (\alpha L)-1} ; \quad \alpha=\frac{u_{\mathrm{d}}+u}{D}
$$

from which one can obtain an expression for the net water flux, given by

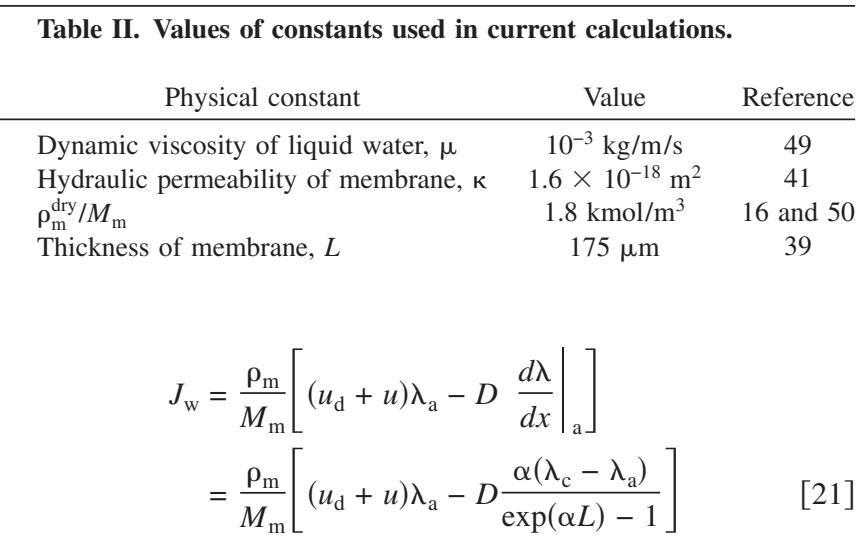

It is understandable from Eq. 20 that the water content, on account of having an exponential profile, is likely to be sensitive to the mesh size, even for the simple case of a constant diffusion coefficient. The following limiting scenario is also interesting

$$
\left.\underset{\alpha \rightarrow 0}{\boldsymbol{L} t} \frac{d \lambda}{d x}\right|_{\mathrm{a}}=\underset{\alpha \rightarrow 0}{\boldsymbol{L} t} \frac{\alpha\left(\lambda_{\mathrm{c}}-\lambda_{\mathrm{a}}\right)}{\exp (\alpha L)-1}=\frac{\lambda_{\mathrm{c}}-\lambda_{\mathrm{a}}}{L}
$$

Equation 22 essentially shows that in the limiting case of diffusion completely dominating convection and drag, the water flux can be computed exactly without discretizing the membrane at all (because $\lambda$ becomes linear). Examples of the use of such approximations are abundant in the literature. 8,9

The above results bring to light the fact that although the membrane is "thin," accurate calculation of the water flux through it requires careful consideration of the number of grid points to be used. It is found that at least 100 cells are needed to accurately calculate the water flux through the membrane if conventional discretization schemes and the finite-volume methods are to be used. When performing large-scale CFD calculations, using 100 or more cells within the membrane alone can lead to tremendous increase in the overall mesh size. Clearly, this is prohibitive, the reason researchers have tended to use a very coarse mesh in the first place. In order to circumvent this problem, we propose to perform the calculations within the membrane off-line and develop a database that can then be used within the context of CFD calculations to generate results that are both accurate and efficient. The development of this database is discussed later.

Parametric studies.-Calculations were performed for various temperatures (assumed to be constant in the membrane), pressure differences between anode and cathode, current densities, and $\left[\lambda_{\mathrm{a}}, \lambda_{\mathrm{c}}\right]$ values. All other quantities in this problem are assumed to be unchanged, and their values are tabulated in Table II. Prior to development of the database, studies were first undertaken to examine the contributions of the various flux components to the net water flux under typical operating conditions. Once again, $\left[\lambda_{\mathrm{a}}, \lambda_{\mathrm{c}}\right]$ values of $[4,14]$ and $[14,4]$ were examined under the conditions of $i_{x}$ $=0.5 \mathrm{~A} / \mathrm{cm}^{2}, T=30^{\circ} \mathrm{C}$, and $p_{\mathrm{c}}-p_{\mathrm{a}}=2$ bars. Figure 4 shows the contributions of drag, convection, and diffusion to the total water

\begin{tabular}{|c|c|c|c|c|}
\hline \multirow{2}{*}{$\begin{array}{l}\text { Number } \\
\text { of cells }\end{array}$} & \multicolumn{2}{|c|}{ Net water flux $\left(\mathrm{kmol} / \mathrm{m}^{2} / \mathrm{s}\right) \times 10^{-5}$} & \multicolumn{2}{|c|}{$\%$ Error (from finest grid) } \\
\hline & {$\left[\lambda_{\mathrm{a}}, \lambda_{\mathrm{c}}\right]=[14,4]$} & {$\left[\lambda_{\mathrm{a}}, \lambda_{\mathrm{c}}\right]=[4,14]$} & {$\left[\lambda_{\mathrm{a}}, \lambda_{\mathrm{c}}\right]=[14,4]$} & {$\left[\lambda_{\mathrm{a}}, \lambda_{\mathrm{c}}\right]=[4,14]$} \\
\hline 5 & 4.754 & -0.123 & 16.6 & 123.2 \\
\hline 10 & 4.408 & 0.211 & 8.1 & 60.3 \\
\hline 20 & 4.231 & 0.383 & 3.8 & 27.9 \\
\hline 40 & 4.143 & 0.468 & 1.6 & 11.9 \\
\hline 80 & 4.100 & 0.511 & 0.5 & 3.8 \\
\hline 160 & 4.078 & 0.531 & 0 & 0 \\
\hline
\end{tabular}

Table I. Numerical errors in water flux calculations associated with the use of various mesh densities. 

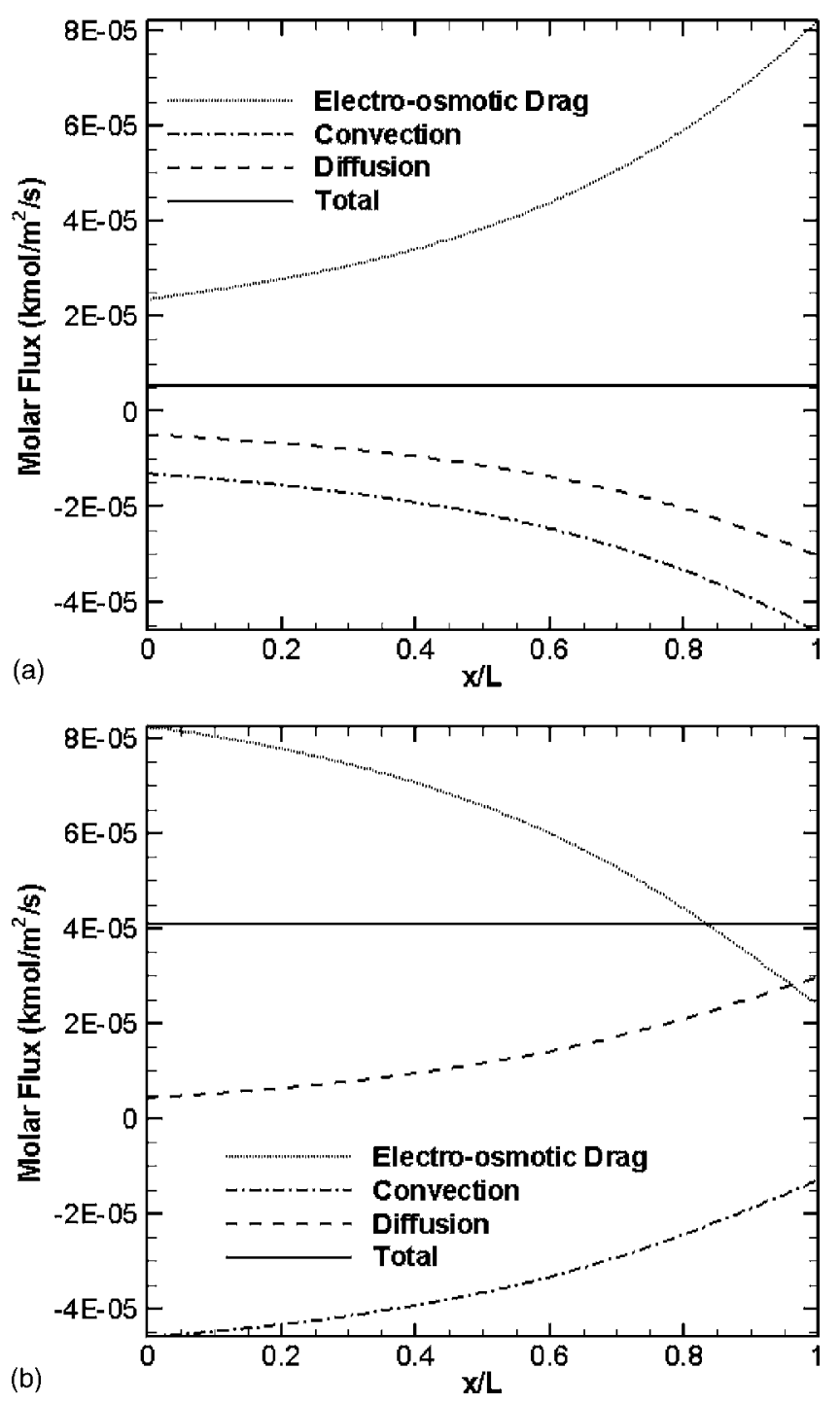

Figure 4. Contributions of various physical mechanisms to water transport across the membrane. (a) $\left[\lambda_{a}, \lambda_{c}\right]=[4,14]$; and (b) $\left[\lambda_{a}, \lambda_{c}\right]=[14,4]$.

flux. It is clear from this figure that convective transport contributes significantly to the net water flux and cannot be neglected if the cathode is pressurized. As discussed earlier, whether convective transport will occur in all regimes of operation or not is a matter of debate. However, the results presented here do show that it is important in liquid-equilibrated membranes. This is particularly important in light of the fact that modern-day PEM fuel cells are generally operated with a pressurized cathode to enhance the partial pressure of the reactants on the cathode side, thereby resulting in an increased reaction rate within the cathode catalyst layer. The second important fact that is highlighted by Fig. 4 is that the finite-volume method, as discussed earlier, indeed conserves the total flux exactly.

Having confirmed the importance of convection, we proceeded to calculate the water flux and average conductivity for all $\left[\lambda_{\mathrm{a}}, \lambda_{\mathrm{c}}\right]$ values under different operating conditions. Figure 5 shows water flux across the membrane for two different pressure differentials at $i_{x}=0.5 \mathrm{~A} / \mathrm{cm}^{2}$ and $T=30^{\circ} \mathrm{C}$. Figure 6 shows the average electrical conductivity of the membrane for the same two cases. It is evident from Fig. 5 that when the pressure difference between the cathode and anode is absent, the water flux is predominantly from anode to cathode (i.e., positive), except in the case when $\lambda_{\mathrm{a}}=0$ and $\lambda_{\mathrm{c}}$ $>20$ when electro-osmotic drag is weak, and the back diffusion results in the net flux being from cathode to anode (i.e., negative).

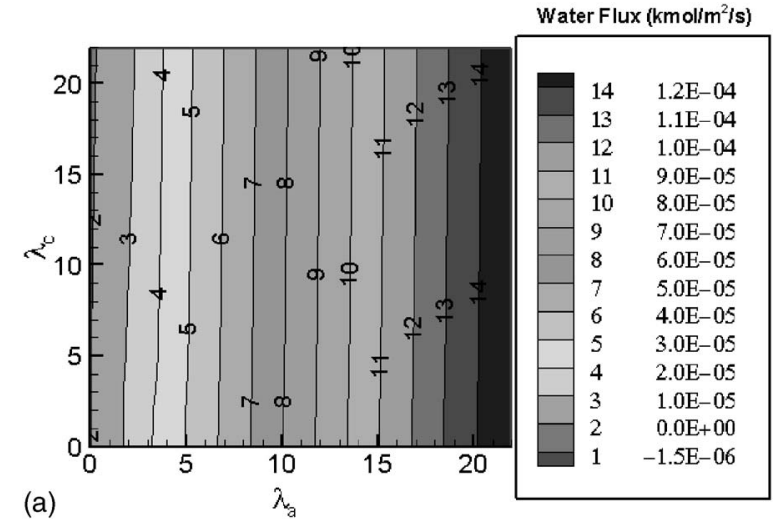

(a)

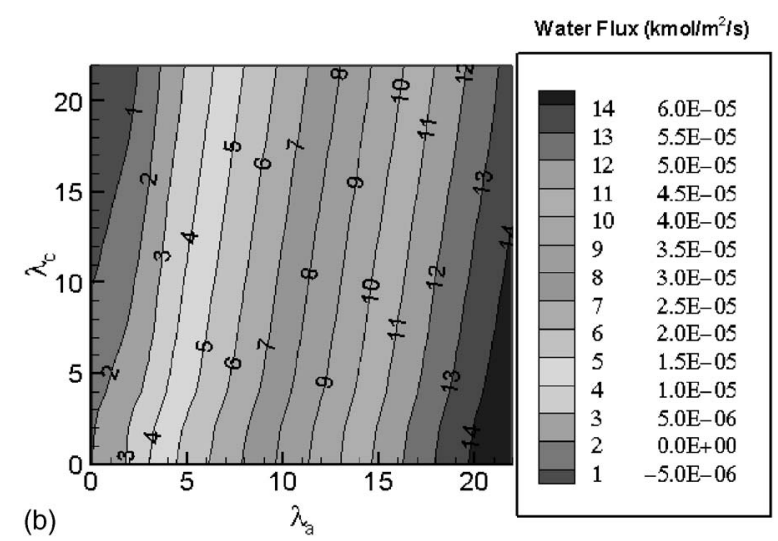

Figure 5. Effect of pressure difference between cathode and anode on water transport. (a) $p_{\mathrm{c}}-p_{\mathrm{a}}=0$ bars: and (b) $p_{\mathrm{c}}-p_{\mathrm{a}}=2$ bars.

When a pressure difference is present, convective transport opposes electro-osmotic drag, and the magnitude of the net water flux from anode to cathode is significantly smaller.

Figures 7 and 8 illustrate the effect of temperature on water transport and electrical conductance of the membrane. In this case, the calculations were performed for $i_{x}=0.5 \mathrm{~A} / \mathrm{cm}^{2}$ and $p_{\mathrm{c}}-p_{\mathrm{a}}$ $=2$ bars. Temperature enhances diffusion of water by increasing the diffusion coefficient (Eq. 8). Thus, at higher temperature, the diffusive flux increases, tending to make the net water flux negative (from cathode to anode). Temperature also has the effect of increasing the average electrical conductivity of the membrane, as evident from Fig. 8 .

Studies were also conducted to investigate the effect of the current density across the membrane on the water transport across the membrane and its average electrical conductivity. Figure 9 shows the effect of current density on the water flux across the membrane. The conditions used for these calculations are $T=80^{\circ} \mathrm{C}$, and $p_{\mathrm{c}}$ $-p_{\mathrm{a}}=2$ bars. At low current density, diffusive and convective transport are comparable to transport by electro-osmotic drag, while at high current density electro-osmotic drag is completely dominant and prevents water from entering the membrane from the cathode side even for cases when the activity of water on the cathode side is very high. These results seem to explain the experimental observation of large quantities of water in the cathode diffusion layer and channels at high current density.

Database development.-From the results and discussion presented in the preceding section, it is clear that the following four parameters independently affect the water flux across the membrane:

1. Temperature affects the diffusive component of the flux by enhancing the diffusion coefficient. Increased diffusion could either increase or decrease the net flux depending on the boundary conditions, i.e., $\left[\lambda_{\mathrm{a}}, \lambda_{\mathrm{c}}\right]$. 

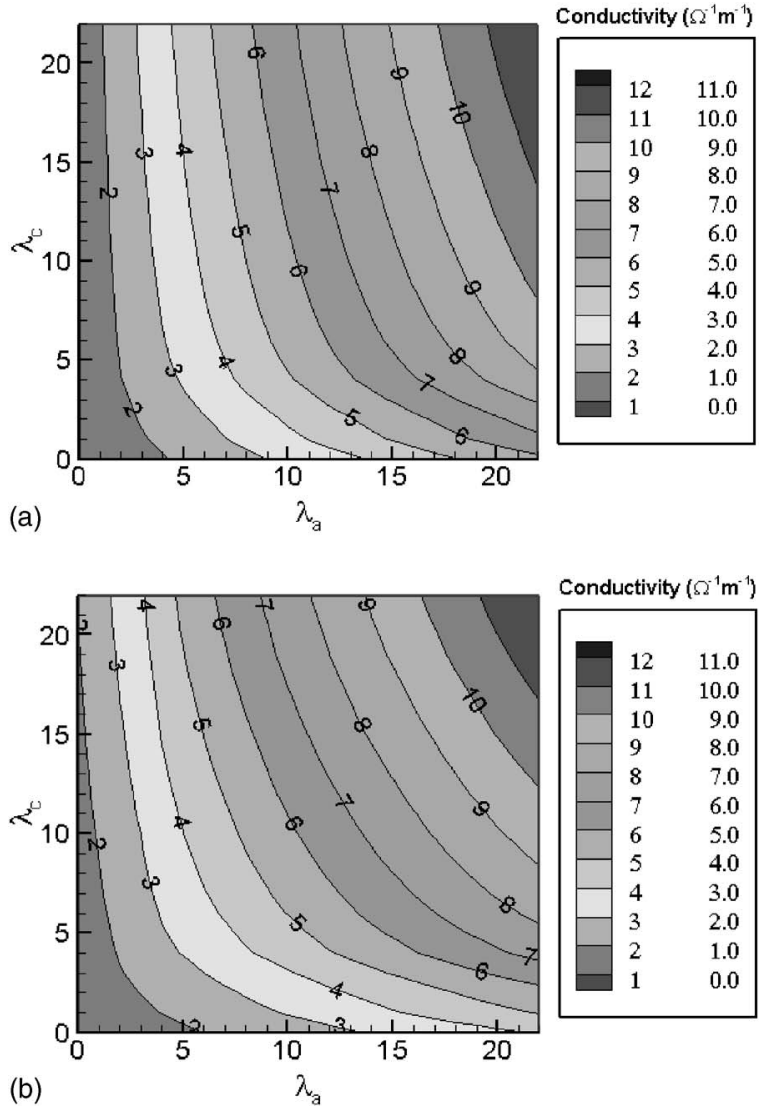

Figure 6. Effect of pressure difference between cathode and anode on average electrical conductivity. (a) $p_{\mathrm{c}}-p_{\mathrm{a}}=0$ bars; and (b) $p_{\mathrm{c}}-p_{\mathrm{a}}=2$ bars

2. Pressure difference between cathode and anode alters the convective component of the flux. An increased pressure difference, i.e., increased $p_{\mathrm{c}}-p_{\mathrm{a}}$, decreases the net flux of water from the anode to the cathode.

3 . The current density across the membrane alters the electroosmotic drag across the membrane. An increase in current density results in increased water flux from anode to cathode.

Based on this discussion, it is clear that the three quantities mentioned above constitute the parameters of the problem and must be varied independently in order to develop an all-inclusive database that can be used by future modelers. This variation of parameters must be performed for each possible $\left[\lambda_{\mathrm{a}}, \lambda_{\mathrm{c}}\right]$ pair. The parameter space of these three parameters, based on information found in the literature and elsewhere, may be summarized as $(i)$ temperature, $T$ : $30-80^{\circ} \mathrm{C}$; (ii) pressure difference, $p_{\mathrm{c}}-p_{\mathrm{a}}: 0-4$ bars; and (iii) current density, $i_{x}: 0-2 \mathrm{~A} / \mathrm{cm}^{2}$. If a database (multidimensional table) is created such that six values are used for $T$ (i.e., $30,40,50,60,70$, and $80^{\circ} \mathrm{C}$ ), five values are used for $p_{\mathrm{c}}-p_{\mathrm{a}}$ (i.e., $0,1,2,3$, and 4 bars), and eleven values are used for $i_{x}$ (i.e., $0-2 \mathrm{~A} / \mathrm{cm}^{2}$ at intervals of $0.2 \mathrm{~A} / \mathrm{cm}^{2}$ ), then this database will have $6 \times 5 \times 11=330$ numbers for each $\left[\lambda_{\mathrm{a}}, \lambda_{\mathrm{c}}\right]$ pair. As discussed previously, both $\lambda_{\mathrm{a}}$ and $\lambda_{\mathrm{c}}$ may vary independently from 0 to 22 . If 13 values are considered for each of $\lambda_{a}$ and $\lambda_{c}$ (i.e., 0-22 at intervals of 2), this will result in a five-dimensional table, consisting of $330 \times 13 \times 13=55,770$ real numbers. This estimate is valid only under the assumption that the interpolation errors within a table with the aforementioned intervals will be acceptable. While the storage of 55,770 real numbers in the memory of a modern-day computer poses no problems, the retrieval of data after interpolation within a five-dimensional table can be quite tricky and most importantly, time-consuming, thereby defeating the purpose of off-line calculations. Another practical problem is that such a large table would be impossible to publish in print
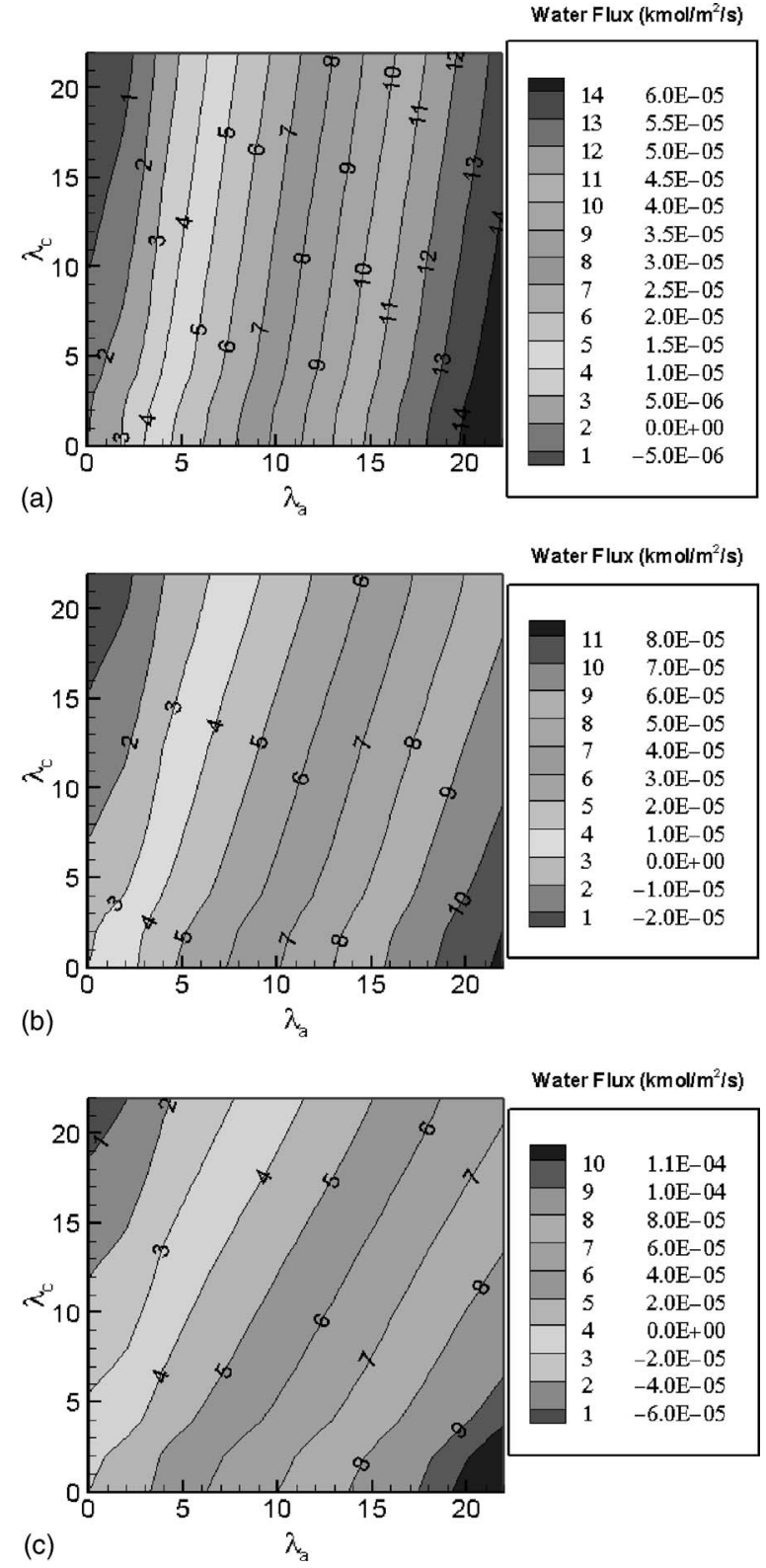

Figure 7. Effect of temperature on water flux across membrane. (a) $30^{\circ} \mathrm{C}$; (b) $50^{\circ} \mathrm{C}$; and (c) $80^{\circ} \mathrm{C}$.

and extremely tedious for others to use unless published in electronic form. For these reasons, we proceeded to analyze our governing equations further with the hope that the data could be presented in more compact form.

Using the transformation $x^{*}=x / L$, Eq. 13 may be rewritten in dimensionless form as

$$
P e_{\mathrm{M}} \frac{d \lambda}{d x^{*}}=\frac{d}{d x^{*}}\left(D_{\lambda}^{\prime} \frac{d \lambda}{d x^{*}}\right)
$$

where $P e_{\mathrm{M}}$ is the Peclet number for mass transfer ${ }^{48}$ and is defined in this particular case as

$$
P e_{\mathrm{M}}=\frac{\left(u_{\mathrm{d}}+u\right) L}{D_{\mathrm{T}}}
$$

Strictly speaking, the Peclet number is used for the ratio of convective to diffusive flux. In this particular case, we have defined the Peclet number to be equal to the ratio of the combined effect of convection and electro-osmotic drag to diffusion, with the notion 

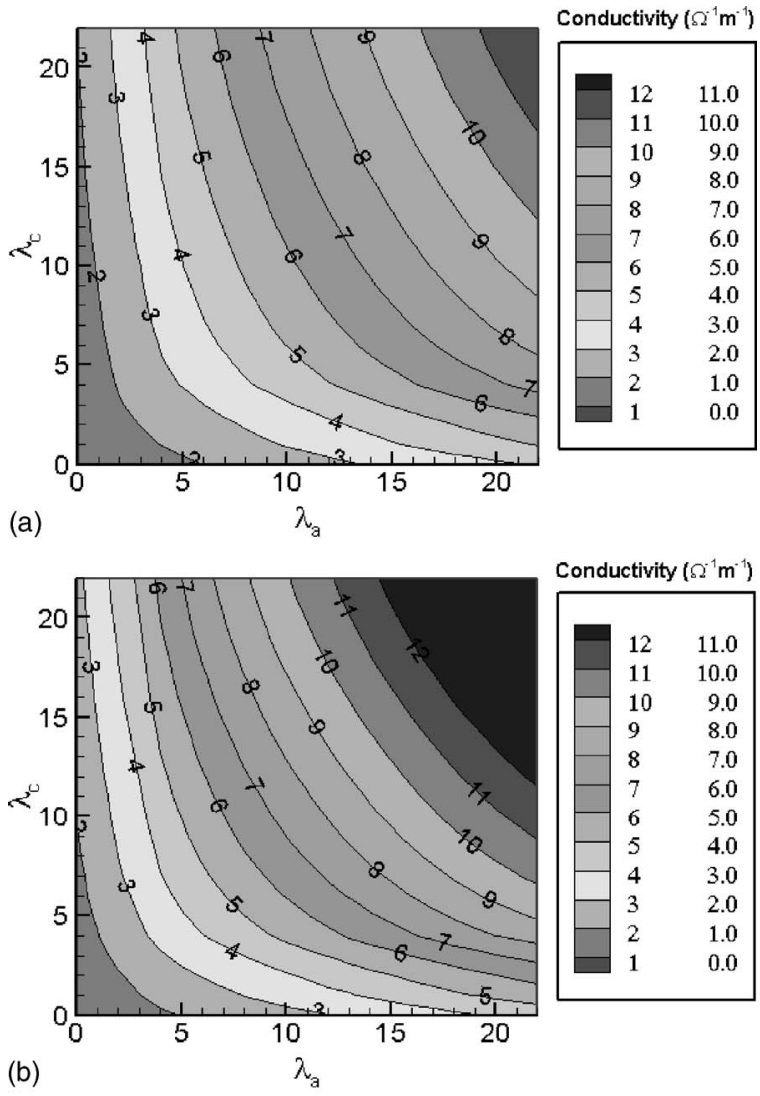

Conductivity $\left(\Omega^{-1} \mathrm{~m}^{-1}\right)$

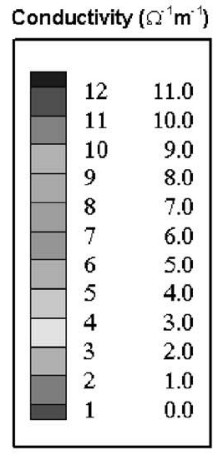

(b)

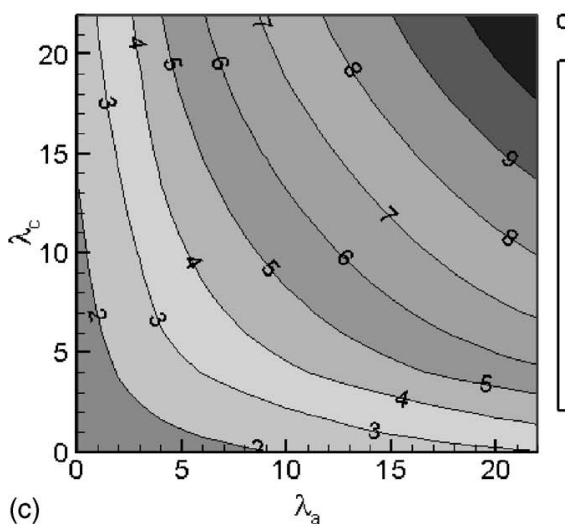

Conductivity $\left(\Omega^{-1} \mathrm{~m}^{-1}\right)$

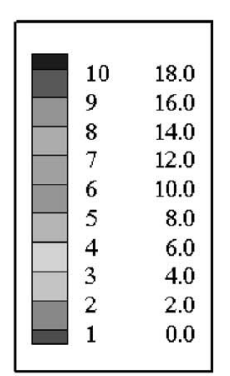

Figure 8. Effect of temperature on the average electrical conductivity of membrane. (a) $30^{\circ} \mathrm{C}$; (b) $50^{\circ} \mathrm{C}$; and (c) $80^{\circ} \mathrm{C}$.

that convection and electro-osmotic drag, although physically completely different, result in the same outcome in a phenomenological sense. That is, they both cause bulk movement of water due to some external mechanism without the need for a concentration gradient. Also, while defining such dimensionless parameters, characteristic velocities are used traditionally. In this case, we are using the actual velocities because the assumption is that they remain unchanged within the membrane. One final point to be made is that depending on the relative magnitudes of the drift velocity and the convective fluid velocity, the Peclet number could also be negative in this particular case, which although unconventional, is simply indicative of the direction of the combined convective and electro-osmotic drag fluxes.

Upon inspection of Eq. 23, it is clear that the functional dependence of the water content (i.e., the solution to the equation) may be
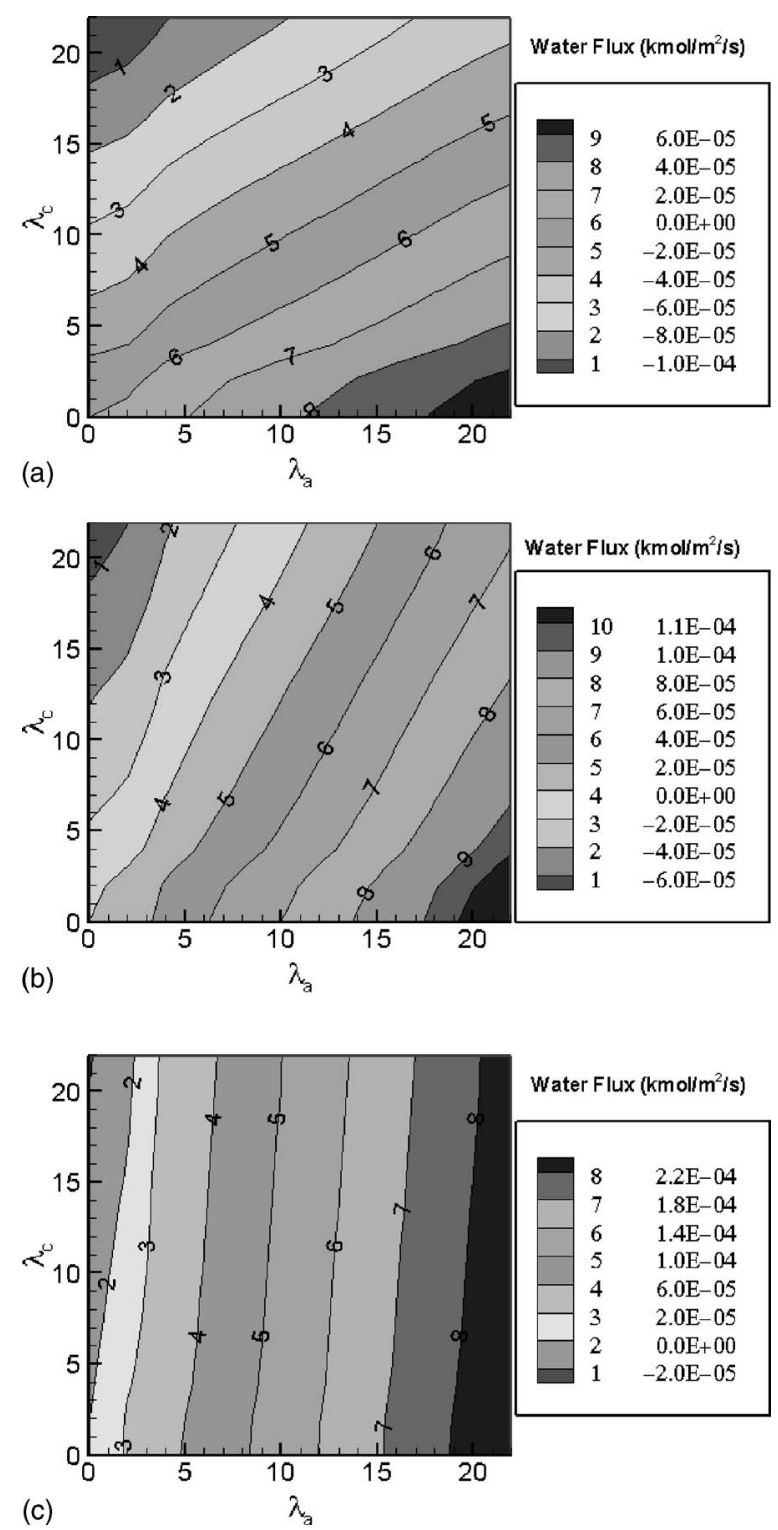

Figure 9. Effect of current density across membrane on water flux across membrane. (a) $i_{x}=0.1 \mathrm{~A} / \mathrm{cm}^{2}$; (b) $i_{x}=0.5 \mathrm{~A} / \mathrm{cm}^{2}$; and (c) $i_{x}=1.2 \mathrm{~A} / \mathrm{cm}^{2}$.

written as $\lambda=\lambda\left(x^{*}, P e_{\mathrm{M}}, \lambda_{\mathrm{a}}, \lambda_{\mathrm{c}}\right)$. The flux of water across the membrane is given by the first part of Eq. 21, and may be rewritten, using a nondimensional space variable, as

$$
J_{\mathrm{w}}=\frac{\rho_{\mathrm{m}}}{M_{\mathrm{m}}} \frac{D_{\mathrm{T}}}{L}\left[P e_{\mathrm{M}} \lambda_{\mathrm{a}}-\left.D_{\lambda}^{\prime} \frac{d \lambda}{d x^{*}}\right|_{\mathrm{a}}\right]
$$

The quantity within parenthesis in Eq. 25 is actually dimensionless, implying that the nondimensional flux of water across the membrane may be written as

$$
J_{\mathrm{w}}^{*}=J_{\mathrm{w}} / \frac{\rho_{\mathrm{m}}}{M_{\mathrm{m}}} \frac{D_{\mathrm{T}}}{L}=\left[P e_{\mathrm{M}} \lambda_{\mathrm{a}}-\left.D_{\lambda}^{\prime} \frac{d \lambda}{d x^{*}}\right|_{\mathrm{a}}\right]
$$

Once again, inspection of Eq. 26 yields $J_{\mathrm{w}}^{*}=J_{\mathrm{w}}^{*}\left(P e_{\mathrm{M}}, \lambda_{\mathrm{a}}, \lambda_{\mathrm{c}}\right)$, which implies that a three-dimensional table with parameters $P e_{\mathrm{M}}, \lambda_{\mathrm{a}}$, and $\lambda_{c}$ is adequate for the storage of the net water flux across the membrane.

Equation 19 may be similarly recast in dimensionless form as 
Table III. Nondimensional water flux, $J_{\mathrm{w}}^{*}$, across the membrane.

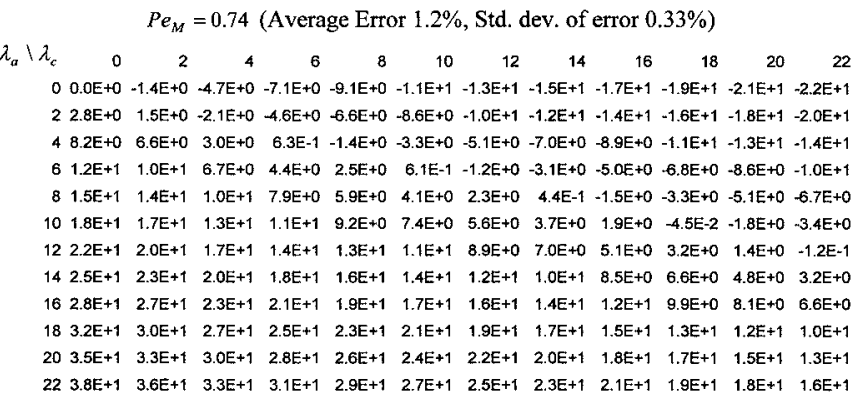

$P e_{M}=1.85$ (Average Error 6\%, Std. dev. of error 3\%)

$\begin{array}{lllllllllllll}\lambda_{a} \backslash \lambda_{c} & 0 & 2 & 4 & 6 & 8 & 10 & 12 & 14 & 16 & 18 & 20 & 22\end{array}$ $0 \quad 0.0 E+0 \quad-7.0 E-1 \quad-2.7 E+0 \quad-4.3 E+0 \quad-5.7 E+0 \quad-7.0 E+0-8.2 E+0-9.5 E+0 \quad-1.1 E+1 \quad-1.2 E+1-1.3 E+1 \quad-1.4 E+1$ $24.4 E+0 \quad 3.7 E+0 \quad 1.1 E+0 .-7.3 E-1-2.2 E+0 \quad-3.5 E+0-4.8 E+0 \quad-6.0 E+0-7.3 E+0-8.5 E+0 \quad-9.7 E+0-1.1 E+1$

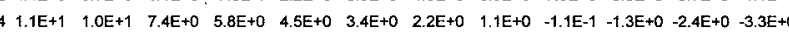

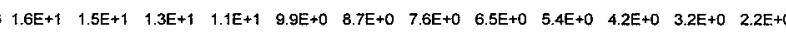
$\begin{array}{lllllllllllll}8 & 2.1 \mathrm{E}+1 & 2.0 \mathrm{E}+1 & 1.7 \mathrm{E}+1 & 1.6 \mathrm{E}+1 & 1.5 \mathrm{E}+1 & 1.4 \mathrm{EE}+1 & 1.3 \mathrm{E}+1 & 1.2 \mathrm{E}+1 & 1.0 \mathrm{E}+1 & 9.3 \mathrm{E}+0 & 8.2 \mathrm{E}+0 & 7.3 \mathrm{E}+0\end{array}$

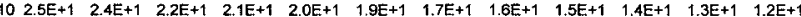

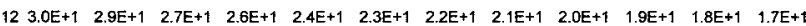

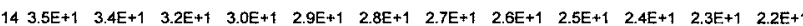

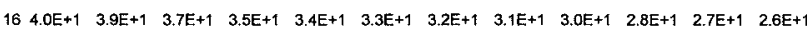

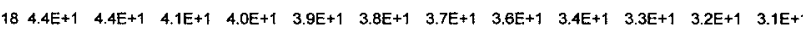
$204.9 E+1 \quad 4.8 E+1 \quad 4.6 E+1 \quad 4.5 E+1 \quad 4.4 E+1 \quad 4.3 E+1 \quad 4.1 E+1 \quad 4.0 E+1 \quad 3.9 E+1 \quad 3.8 E+1 \quad 3.7 E+1 \quad 3.6 E+1$ $22 \quad 5.3 \mathrm{E}+1 \quad 5.2 \mathrm{E}+1 \quad 5.0 \mathrm{E}+1 \quad 4.9 \mathrm{E}+1 \quad 4.8 \mathrm{E}+1 \quad 4.7 \mathrm{E}+1 \quad 4.6 \mathrm{E}+1 \quad 4.5 \mathrm{E}+1 \quad 4.3 \mathrm{E}+1 \quad 4.2 \mathrm{E}+1 \quad 4.1 \mathrm{E}+1 \quad 4.1 \mathrm{E}+1$

$P e_{M}=3.7$ (Average Error 3.3\%, Std. dev. of error $1.2 \%$ )

$\begin{array}{lllllllllllll}\lambda_{a} \backslash \lambda_{c} & 0 & 2 & 4 & 6 & 8 & 10 & 12 & 14 & 16 & 18 & 20 & 22\end{array}$ $00.0 E+0 \quad-1.9 E-1-8.1 E-1-1.4 E+0-2.0 E+0-2.6 E+0-3.1 E+0-3.6 E+0-4.2 E+0-4.7 E+0 \quad-5.2 E+0-5.7 E+0$ $\begin{array}{lllllllllllll}2 & 7.6 \mathrm{E}+0 & 7.4 \mathrm{E}+0 & 6.1 \mathrm{E}+0 & 5.0 \mathrm{E}+0 & 4.2 \mathrm{E}+0 & 3.4 \mathrm{E}+0 & 2.8 \mathrm{E}+0 & 2.2 \mathrm{E}+0 & 1.5 \mathrm{E}+0 & 9.3 \mathrm{E}-1 & 3.8 \mathrm{E}-1 & -8.5 \mathrm{E}-2\end{array}$

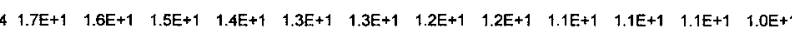

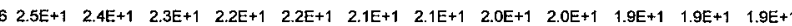

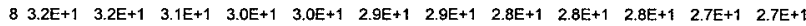
$10 \quad 4.0 \mathrm{E}+1 \quad 3.9 \mathrm{E}+1 \quad 3.8 \mathrm{E}+1 \quad 3.8 \mathrm{E}+1 \quad 3.7 \mathrm{E}+1 \quad 3.7 \mathrm{E}+1 \quad 3.7 \mathrm{E}+1 \quad 3.6 \mathrm{E}+1 \quad 3.6 \mathrm{E}+1 \quad 3.5 \mathrm{E}+1 \quad 3.5 \mathrm{E}+1 \quad 3.5 \mathrm{E}+1$ $12 \quad 4.7 E+1 \quad 4.7 E+1 \quad 4.6 E+1 \quad 4.6 E+1 \quad 4.5 E+1 \quad 4.5 E+1 \quad 4.4 E+1 \quad 4.4 E+1 \quad 4.4 E+1 \quad 4.3 E+1 \quad 4.3 E+1 \quad 4.2 E+1$ $14 \quad 5.5 E+1 \quad 5.5 E+1 \quad 5.4 E+1 \quad 5.4 E+1 \quad 5.3 E+1 \quad 5.3 E+1 \quad 5.2 E+1 \quad 5.2 E+1 \quad 5.1 E+1 \quad 5.1 E+1 \quad 5.0 E+1 \quad 5.0 E+1$

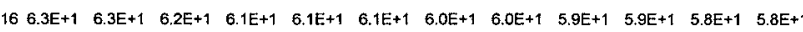
$18 \quad 7.1 \mathrm{E}+1 \quad 7.1 \mathrm{E}+1 \quad 7.0 \mathrm{E}+1 \quad 6.9 \mathrm{E}+1 \quad 6.9 \mathrm{E}+1 \quad 6.8 \mathrm{E}+1 \quad 6.8 \mathrm{E}+1 \quad 6.8 \mathrm{E}+1 \quad 6.7 \mathrm{E}+1 \quad 6.7 \mathrm{E}+1 \quad 6.6 \mathrm{E}+1 \quad 6.6 \mathrm{E}+1$ $207.9 \mathrm{E}+1 \quad 7.8 \mathrm{E}+1 \quad 7.7 \mathrm{E}+1 \quad 7.7 \mathrm{E}+1 \quad 7.6 \mathrm{E}+1 \quad 7.6 \mathrm{E}+1 \quad 7.6 \mathrm{E}+1 \quad 7.5 \mathrm{E}+1 \quad 7.5 \mathrm{E}+1 \quad 7.4 \mathrm{E}+1 \quad 7.4 \mathrm{E}+1 \quad 7.4 \mathrm{E}+1$

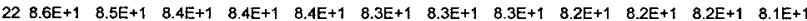

$P e_{M}=5.05$ (Average Error 1.5\%, Std. dev. of error $0.37 \%$ )

$\begin{array}{lllllllllllll}\lambda_{a} \backslash \lambda_{c} & 0 & 2 & 4 & 6 & 8 & 10 & 12 & 14 & 16 & 18 & 20 & 22\end{array}$ $0 \quad 0.0 E+0 \quad-8.1 E-2 \quad-3.3 E-1 \quad-6.0 E-1 \quad-8.6 E-1 \quad-1.1 E+0-1.4 E+0-1.7 E+0-1.9 E+0 \quad-2.2 E+0 \quad-2.5 E+0-2.7 E+0$ $\begin{array}{lllllllllllll}2 & 1.0 \mathrm{E}+1 & 1.0 \mathrm{E}+1 & 9.4 \mathrm{E}+0 & 8.6 \mathrm{EE}+0 & 8.1 \mathrm{E}+0 & 7.6 \mathrm{E}+0 & 7.2 \mathrm{E}+0 & 6.7 \mathrm{E}+0 & 6.3 \mathrm{E}+0 & 5.9 \mathrm{E}+0 & 5.6 \mathrm{E}+0 & 5.3 \mathrm{E}+0\end{array}$

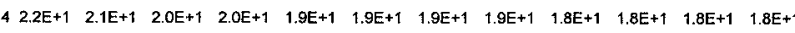

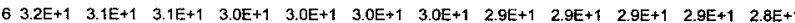

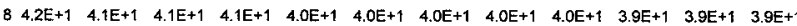

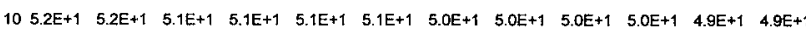

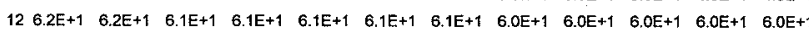

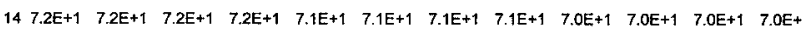

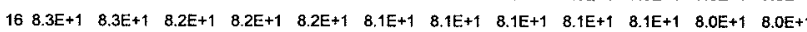
$\begin{array}{llllllllllllllll}18 & 9.3 E+1 & 9.3 E+1 & 9.3 E+1 & 9.2 E+1 & 9.2 E+1 & 9.2 E+1 & 9.2 E+1 & 9.1 E+1 & 9.1 E+1 & 9.1 E+1 & 9.1 E+1 & 9.1 E+1\end{array}$

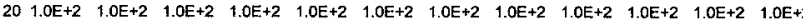

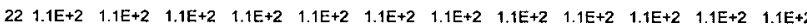

\section{$P e_{M}=8.38$ (Average Error $0.4 \%$, Std. dev. of error $0.1 \%$ )}

$\begin{array}{lllllllllllll}\lambda_{a} \backslash \lambda_{\mathrm{c}} & 0 & 2 & 4 & 6 & 8 & 10 & 12 & 14 & 16 & 18 & 20 & 22\end{array}$

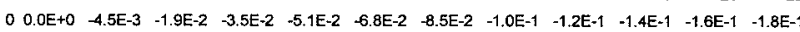

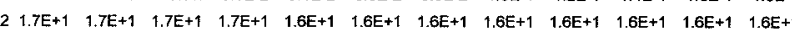

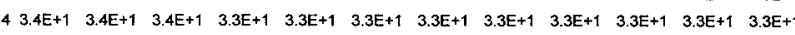

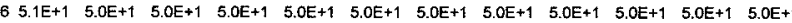
$\begin{array}{lllllllllllll}8 & 6.7 \mathrm{E}+1 & 6.7 \mathrm{E}+1 & 6.7 \mathrm{E}+1 & 6.7 \mathrm{E}+1 & 6.7 \mathrm{E}+1 & 6.7 \mathrm{E}+1 & 6.7 \mathrm{E}+1 & 6.7 \mathrm{E}+1 & 6.7 \mathrm{E}+1 & 6.7 \mathrm{E}+1 & 6.7 \mathrm{E}+1 & 6.7 \mathrm{E}+1\end{array}$

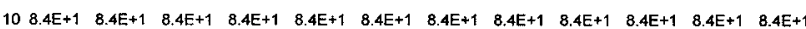

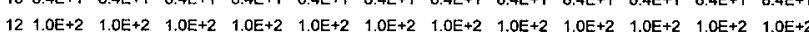

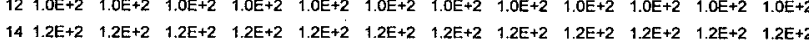

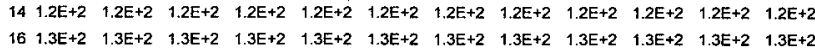

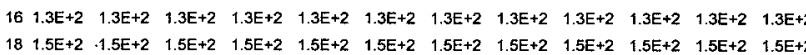

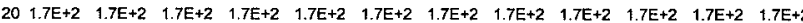

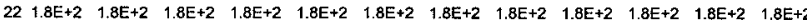

\section{$P e_{M}=10.78$ (Average Error $0.16 \%$, Std. dev. of error $0.05 \%$ )}

$\begin{array}{lllllllllllll}\lambda_{a} \backslash \lambda_{c} & 0 & 2 & 4 & 6 & 8 & 10 & 12 & 14 & 16 & 18 & 20 & 22\end{array}$

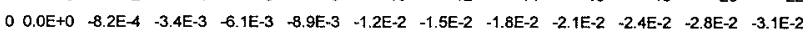

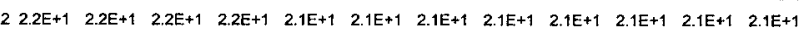

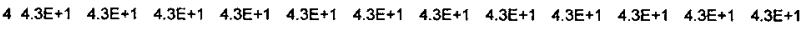

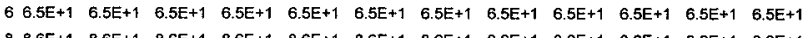
$\begin{array}{lllllllllllll}8 & 8.6 \mathrm{E}+1 & 8.6 \mathrm{E}+1 & 8.6 \mathrm{E}+1 & 8.6 \mathrm{E}+1 & 8.6 \mathrm{E}+1 & 8.6 \mathrm{EE}+1 & 8.6 \mathrm{E}+1 & 8.6 \mathrm{EE}+1 & 8.6 \mathrm{E}+1 & 8.6 \mathrm{E}+1 & 8.6 \mathrm{E}+1 & 8.6 \mathrm{E}+1\end{array}$

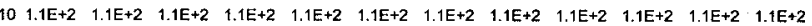

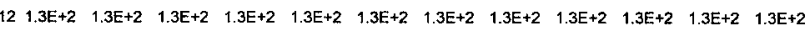

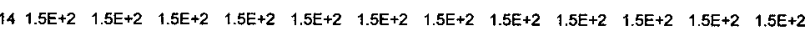

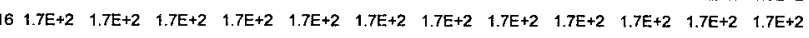
$\begin{array}{lllllllllllll}18 & 1.9 \mathrm{E}+2 & 1.9 \mathrm{E}+2 & 1.9 \mathrm{E}+2 & 1.9 \mathrm{E}+2 & 1.9 \mathrm{E}+2 & 1.9 \mathrm{E}+2 & 1.9 \mathrm{E}+2 & 1.9 \mathrm{E}+2 & 1.9 \mathrm{E}+2 & 1.9 \mathrm{E}+2 & 1.9 \mathrm{E}+2 & 1.9 \mathrm{E}+2\end{array}$

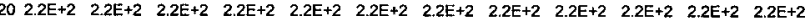

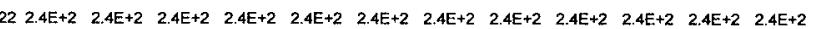

$$
P e_{M}=13.74 \text { (Average Error } 0.05 \% \text {, Std. dev. of error } 0.016 \% \text { ) }
$$

$\begin{array}{lllllllllllll}\lambda_{a} \backslash \lambda_{c} & 0 & 2 & 4 & 6 & 8 & 10 & 12 & 14 & 16 & 18 & 20 & 22\end{array}$

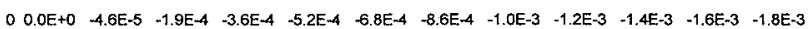

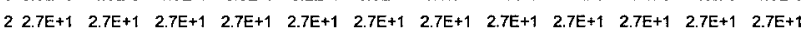
$\begin{array}{lllllllllllll}4 & 5.5 \mathrm{E}+1 & 5.5 \mathrm{E}+1 & 5.5 \mathrm{E}+1 & 5.5 \mathrm{E}+1 & 5.5 \mathrm{E}+1 & 5.5 \mathrm{EE}+1 & 5.5 \mathrm{E}+1 & 5.5 \mathrm{E}+1 & 5.5 \mathrm{E}+1 & 5.5 \mathrm{E}+1 & 5.5 \mathrm{E}+1 & 5.5 \mathrm{E}+1\end{array}$

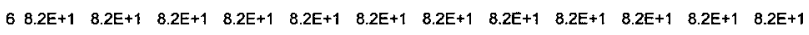

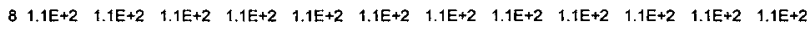

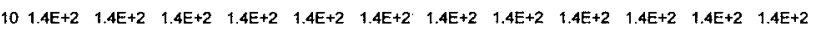

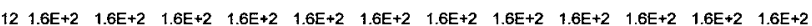

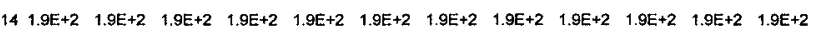

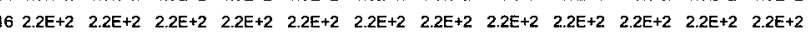

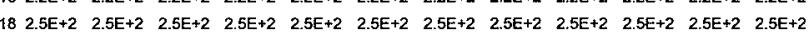

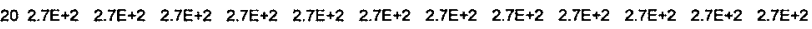

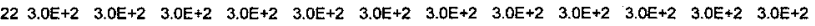

$$
P e_{M}=16.5 \text { (Average Error } 0.022 \%, \text { Std. dev. of error } 0.007 \% \text { ) }
$$

$\begin{array}{lllllllllllll}\lambda_{a} \backslash \lambda_{c} & 0 & 2 & 4 & 6 & 8 & 10 & 12 & 14 & 16 & 18 & 20 & 22\end{array}$

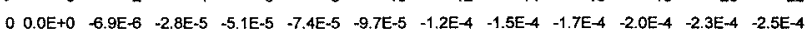

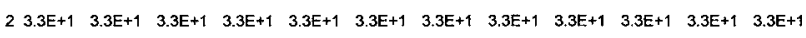
$46.6 \mathrm{E}+1 \quad 6.6 \mathrm{E}+1 \quad 6.6 \mathrm{E}+1 \quad 6.6 \mathrm{E}+1 \quad 6.6 \mathrm{E}+1 \quad 6.6 \mathrm{E}+1 \quad 6.6 \mathrm{E}+1 \quad 6.6 \mathrm{E}+1 \quad 6.6 \mathrm{E}+1 \quad 6.6 \mathrm{E}+1 \quad 6.6 \mathrm{E}+1 \quad 6.6 \mathrm{E}+1$

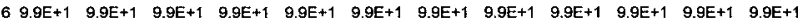

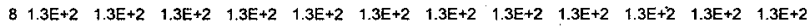

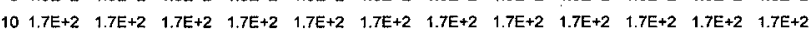

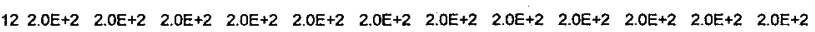

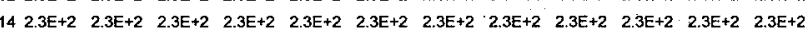

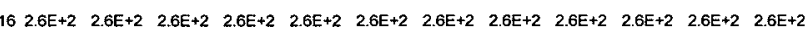

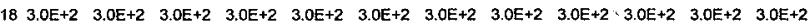

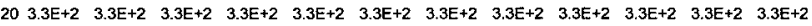

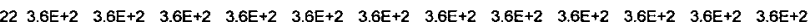

$$
P e_{M}=19.7 \text { (Average Error } 0.007 \% \text {, Std. dev. of error 0.003\%) }
$$

$\begin{array}{llllllllllll}\lambda_{a} \backslash \lambda_{c} & 0 & 2 & 4 & 6 & 8 & 10 & 12 & 14 & 16 & 18 & 20\end{array}$ $00.0 E+0 \quad-3.8 E-7 \quad-1.5 E-6 \quad-2.7 E-6 \quad-3.9 E-6 \quad-5.2 E-6 \quad-6.5 E-6 \quad-7.8 E-6 \quad-9.3 E-6 \quad-1.1 E-5 \quad-1.2 E-5 \quad-1.3 E-5$

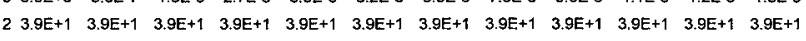
$\begin{array}{llllllllllll}4.9 \mathrm{E}+1 & 7.9 \mathrm{E}+1 & 7.9 \mathrm{E}+1 & 7.9 \mathrm{E}+1 & 7.9 \mathrm{E}+1 & 7.9 \mathrm{E}+1 & 7.9 \mathrm{E}+1 & 7.9 \mathrm{E}+1 & 7.9 \mathrm{E}+1 & 7.9 \mathrm{E}+1 & 7.9 \mathrm{E}+1 & 7.9 \mathrm{E}+1\end{array}$

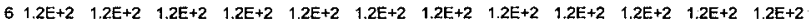

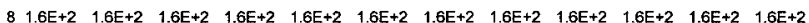

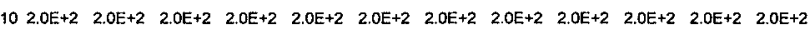

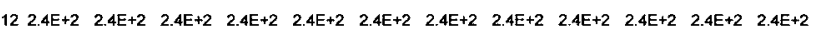

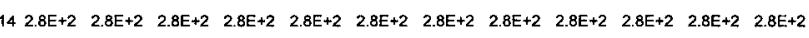

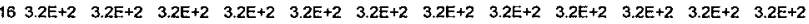

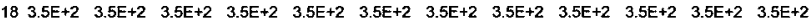

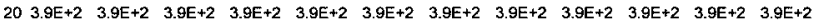

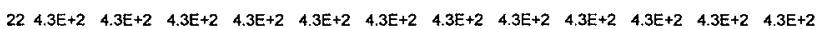


Table IV. Nondimensional average electrical conductivity of membrane, $\left\langle\sigma_{m}^{*}\right\rangle$.

\section{$P e_{M}=0.74$ (Average Error 1.7\%, Std. dev. of error $0.72 \%$ )}

$\begin{array}{lllllllllllll}\lambda_{a} \backslash \lambda_{c} & 0 & 2 & 4 & 6 & 8 & 10 & 12 & 14 & 16 & 18 & 20 & 22\end{array}$

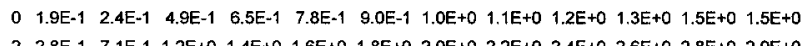

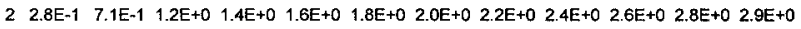
$4 \quad 6.1 E-1 \quad 1.2 E+01.7 E+0 \quad 2.2 E+0 \quad 2.5 E+0 \quad 2.8 E+0 \quad 3.1 E+0 \quad 3.4 E+03.7 E+0 \quad 4.0 E+0 \quad 4.2 E+0 \quad 4.4 E+0$

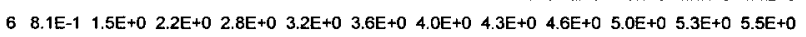
$8 \quad 9.9 E-1 \quad 1.8 E+0 \quad 2.7 E+0 \quad 3.3 E+0 \quad 3.8 E+0 \quad 4.2 E+0 \quad 4.7 E+0 \quad 5.1 E+0 \quad 5.4 E+0 \quad 5.8 E+0 \quad 6.1 E+0 \quad 6.4 E+0$ $10 \quad 1.2 \mathrm{E}+0 \quad 2.1 \mathrm{E}+0 \quad 3.1 \mathrm{E}+0 \quad 3.8 \mathrm{E}+0 \quad 4.3 \mathrm{E}+0 \quad 4.8 \mathrm{E}+0 \quad 5.3 \mathrm{E}+0 \quad 5.7 \mathrm{E}+0 \quad 6.1 \mathrm{E}+0 \quad 6.5 \mathrm{E}+0 \quad 6.9 \mathrm{E}+0 \quad 7.2 \mathrm{E}+0$ $12 \quad 1.3 \mathrm{E}+0 \quad 2.4 \mathrm{E}+0 \quad 3.5 \mathrm{E}+0 \quad 4.3 \mathrm{E}+0 \quad 4.9 \mathrm{E}+0 \quad 5.4 \mathrm{E}+0 \quad 5.9 \mathrm{E}+0 \quad 6.3 \mathrm{E}+0 \quad 6.8 \mathrm{E}+0 \quad 7.2 \mathrm{E}+0 \quad 7.5 \mathrm{E}+0 \quad 7.9 \mathrm{E}+0$ $14 \quad 1.5 E+0 \quad 2.6 E+0 \quad 3.9 E+0 \quad 4.7 E+0 \quad 5.4 E+0 \quad 5.9 E+0 \quad 6.4 E+0 \quad 6.9 E+0 \quad 7.4 E+0 \quad 7.8 E+0 \quad 8.2 E+0 \quad 8.5 E+0$

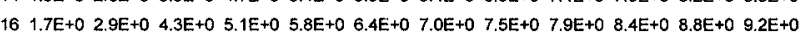
$18 \quad 1.9 E+0 \quad 3.2 E+0 \quad 4.6 E+0 \quad 5.6 E+0 \quad 6.3 E+0 \quad 6.9 E+0 \quad 7.5 E+0 \quad 8.0 E+0 \quad 8.5 E+0 \quad 9.0 E+0 \quad 9.4 E+0 \quad 9.8 E+0$ $202.0 E+0 \quad 3.4 E+0 \quad 5.0 E+0 \quad 6.0 E+0 \quad 6.7 E+0 \quad 7.4 E+0 \quad 7.9 E+0 \quad 8.5 E+0 \quad 9.0 E+0 \quad 9.5 E+0 \quad 1.0 E+1 \quad 1.0 E+1$ $222.2 \mathrm{E}+0 \quad 3.7 \mathrm{E}+0 \quad 5.3 \mathrm{E}+0 \quad 6.3 \mathrm{E}+0 \quad 7.1 \mathrm{E}+0 \quad 7.8 \mathrm{E}+0 \quad 8.4 \mathrm{E}+0 \quad 8.9 \mathrm{E}+0 \quad 9.5 \mathrm{E}+0 \quad 1.0 \mathrm{E}+1 \quad 1.1 \mathrm{E}+1 \quad 1.1 \mathrm{E}+1$

\section{$P e_{M}=1.85$ (Average Error $1.8 \%$, Std. dev. of error $0.77 \%$ )}

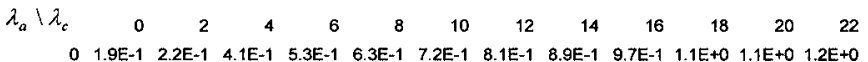

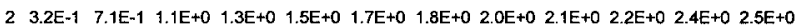

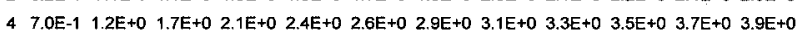

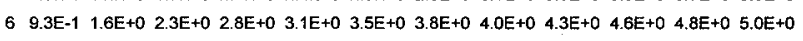

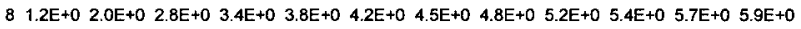

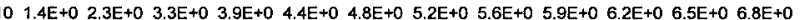
$12 \quad 1.6 \mathrm{E}+0 \quad 2.7 \mathrm{E}+0 \quad 3.8 \mathrm{E}+0 \quad 4.5 \mathrm{E}+0 \quad 5.0 \mathrm{E}+0 \quad 5.5 \mathrm{E}+0 \quad 5.9 \mathrm{E}+0 \quad 6.3 \mathrm{E}+0 \quad 6.6 \mathrm{E}+0 \quad 7.0 \mathrm{E}+0 \quad 7.3 \mathrm{E}+0 \quad 7.5 \mathrm{E}+0$ $14 \quad 1.8 \mathrm{E}+0 \quad 3.0 \mathrm{E}+0 \quad 4.3 \mathrm{E}+0 \quad 5.0 \mathrm{E}+0 \quad 5.6 \mathrm{E}+0 \quad 6.1 \mathrm{E}+0 \quad 6.5 \mathrm{E}+0 \quad 6.9 \mathrm{E}+0 \quad 7.3 \mathrm{E}+0 \quad 7.7 \mathrm{E}+0 \quad 8.0 \mathrm{E}+0 \quad 8.3 \mathrm{E}+0$ 16 2.1E+0 3.4E+0 4.7E+0 5.5E+0 6.1E+0 6.6E+0 7.1E+0 7.5E+0 7.9E+0 8.3E+0 $8.7 \mathrm{E}+0$ 9.0E+0 $18 \quad 2.3 \mathrm{E}+0 \quad 3.7 \mathrm{E}+0 \quad 5.1 \mathrm{E}+0 \quad 6.0 \mathrm{E}+0 \quad 6.7 \mathrm{E}+0.7 .2 \mathrm{E}+0.7 .7 \mathrm{E}+0 \quad 8.1 \mathrm{E}+0 \quad 8.6 \mathrm{EE}+0 \quad 9.0 \mathrm{EE}+0 \quad 9.3 \mathrm{E}+0 \quad 9.7 \mathrm{E}+0$ $20 \quad 2.5 \mathrm{E}+0 \quad 4.0 \mathrm{E}+0 \quad 5.6 \mathrm{E}+0 \quad 6.5 \mathrm{E}+0 \quad 7.2 \mathrm{E}+0 \quad 7.7 \mathrm{E}+0 \quad 8.2 \mathrm{E}+0 \quad 8.7 \mathrm{E}+0 \quad 9.2 \mathrm{E}+0 \quad 9.6 \mathrm{E}+0 \quad 1.0 \mathrm{E}+1 \quad 1.0 \mathrm{EE}+1$ $22 \quad 2.7 \mathrm{E}+0 \quad 4.3 \mathrm{E}+0 \quad 5.9 \mathrm{E}+0 \quad 6.9 \mathrm{E}+0 \quad 7.6 \mathrm{E}+0 \quad 8.2 \mathrm{E}+0 \quad 8.7 \mathrm{E}+0 \quad 9.2 \mathrm{E}+0$ 9. $9.7 \mathrm{E}+0 \quad 1.0 \mathrm{E}+1 \quad 1.1 \mathrm{E}+1 \quad 1.1 \mathrm{E}+1$

\section{$P e_{M}=3.7$ (Average Error $2.5 \%$, Std. dev. of error $0.92 \%$ )}

$\begin{array}{lllllllllllll}\lambda_{a} \backslash \lambda_{c} & 0 & 2 & 4 & 6 & 8 & 10 & 12 & 14 & 16 & 18 & 20 & 22\end{array}$ $\begin{array}{lllllllll}0 & 1.9 E-1 & 2.1 E-1 & 3.1 E-1 & 3.8 E-1 & 4.4 E-1 & 4.9 E-1 & 5.4 E-1 & 5.9 E-1 \\ 2 & 6.4 E-1 & 6.8 E-1 & 7.3 E-1 & 7.6 E-1\end{array}$

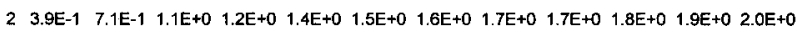

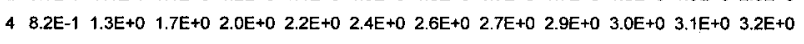

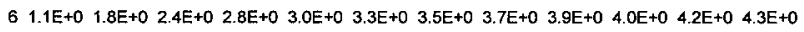
$8 \quad 1.5 E+0 \quad 2.3 E+0 \quad 3.0 E+0 \quad 3.5 E+0 \quad 3.8 E+0 \quad 4.1 E+0 \quad 4.3 E+0 \quad 4.6 E+0 \quad 4.8 E+0 \quad 5.0 E+0 \quad 5.2 E+0 \quad 5.3 E+0$ $10 \quad 1.8 \mathrm{E}+0 \quad 2.7 \mathrm{E}+0 \quad 3.6 \mathrm{E}+0 \quad 4.1 \mathrm{E}+0 \quad 4.5 \mathrm{E}+0 \quad 4.8 \mathrm{E}+0 \quad 5.1 \mathrm{E}+0 \quad 5.4 \mathrm{E}+0 \quad 5.6 \mathrm{E}+0 \quad 5.8 \mathrm{E}+0 \quad 6.1 \mathrm{E}+0 \quad 6.2 \mathrm{E}+0$ $12 \quad 2.1 E+0 \quad 3.2 E+0 \quad 4.2 E+0 \quad 4.8 E+0 \quad 5.2 E+0 \quad 5.6 E+0 \quad 5.9 E+0 \quad 6.2 E+0 \quad 6.4 E+0 \quad 6.7 E+0 \quad 6.9 E+0 \quad 7.1 E+0$ $142.4 \mathrm{E}+0 \quad 3.7 \mathrm{E}+0 \quad 4.8 \mathrm{E}+0 \quad 5.4 \mathrm{E}+0 \quad 5.9 \mathrm{E}+0 \quad 6.3 \mathrm{E}+0 \quad 6.6 \mathrm{E}+0 \quad 6.9 \mathrm{E}+0 \quad 7.2 \mathrm{E}+0 \quad 7.5 \mathrm{E}+0 \quad 7.7 \mathrm{E}+0 \quad 7.9 \mathrm{E}+0$ $16 \quad 2.8 \mathrm{E}+0 \quad 4.1 \mathrm{E}+0 \quad 5.4 \mathrm{E}+0 \quad 6.1 \mathrm{E}+0 \quad 6.5 \mathrm{E}+0 \quad 6.9 \mathrm{E}+0 \quad 7.3 \mathrm{E}+0 \quad 7.6 \mathrm{E}+0 \quad 7.9 \mathrm{E}+0 \quad 8.2 \mathrm{E}+0 \quad 8.5 \mathrm{E}+0 \quad 8.7 \mathrm{E}+0$ $183.1 \mathrm{E}+0 \quad 4.6 \mathrm{E}+0 \quad 5.9 \mathrm{E}+0 \quad 6.7 \mathrm{E}+0 \quad 7.2 \mathrm{E}+0 \quad 7.6 \mathrm{E}+0 \quad 8.0 \mathrm{E}+0 \quad 8.3 \mathrm{E}+0 \quad 8.7 \mathrm{E}+0 \quad 9.0 \mathrm{E}+0 \quad 9.2 \mathrm{E}+0 \quad 9.5 \mathrm{E}+0$

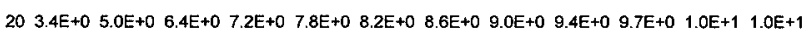

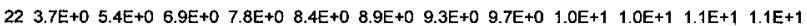

\section{$P e_{M}=5.05$ (Average Error 3.5\%, Std. dev. of error 1.13\%)}

$\begin{array}{lllllllllllll}\lambda_{a} \backslash \lambda_{c} & 0 & 2 & 4 & 6 & 8 & 10 & 12 & 14 & 16 & 18 & 20 & 22\end{array}$

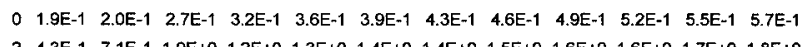

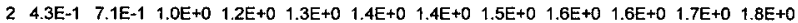

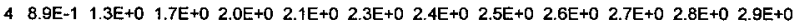

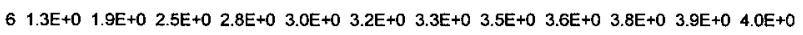
$8 \quad 1.7 E+0 \quad 2.4 E+0 \quad 3.1 E+0 \quad 3.5 E+0 \quad 3.8 E+0 \quad 4.0 E+0 \quad 4.2 E+0 \quad 4.4 E+0 \quad 4.6 E+0 \quad 4.7 E+0 \quad 4.9 E+0 \quad 5.0 E+0$ $102.1 \mathrm{E}+0 \quad 3.0 \mathrm{E}+0 \quad 3.8 \mathrm{E}+0 \quad 4.3 \mathrm{E}+0 \quad 4.6 \mathrm{E}+0 \quad 4.8 \mathrm{E}+0 \quad 5.1 \mathrm{E}+0 \quad 5.3 \mathrm{E}+0 \quad 5.5 \mathrm{E}+0 \quad 5.7 \mathrm{E}+0 \quad 5.8 \mathrm{E}+0 \quad 6.0 \mathrm{E}+0$

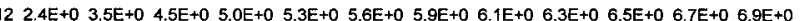
$142.8 \mathrm{E}+0 \quad 4.1 \mathrm{E}+0 \quad 5.1 \mathrm{E}+0 \quad 5.7 \mathrm{E}+0 \quad 6.1 \mathrm{E}+0 \quad 6.4 \mathrm{E}+0 \quad 6.6 \mathrm{E}+0 \quad 6.9 \mathrm{E}+0 \quad 7.1 \mathrm{E}+0 \quad 7.4 \mathrm{E}+0 \quad 7.6 \mathrm{E}+0.7 .7 \mathrm{E}+0$ $16 \quad 3.2 \mathrm{E}+0 \quad 4.6 \mathrm{E}+0 \quad 5.7 \mathrm{E}+0 \quad 6.3 \mathrm{E}+0 \quad 6.8 \mathrm{E}+0 \quad 7.1 \mathrm{E}+0 \quad 7.4 \mathrm{E}+0 \quad 7.7 \mathrm{E}+0 \quad 7.9 \mathrm{E}+0 \quad 8.2 \mathrm{E}+0 \quad 8.4 \mathrm{E}+0 \quad 8.6 \mathrm{E}+0$ $18 \quad 3.6 \mathrm{E}+0 \quad 5.1 \mathrm{E}+0 \quad 6.3 \mathrm{E}+0 \quad 7.0 \mathrm{E}+0 \quad 7.5 \mathrm{E}+0 \quad 7.8 \mathrm{E}+0 \quad 8.1 \mathrm{E}+0 \quad 8.4 \mathrm{E}+0 \quad 8.7 \mathrm{E}+0 \quad 9.0 \mathrm{E}+0 \quad 9.2 \mathrm{E}+0 \quad 9.4 \mathrm{E}+0$ $20 \quad 4.0 E+0 \quad 5.6 E+0 \quad 6.9 E+0 \quad 7.6 E+08.1 E+0 \quad 8.5 E+08.9 E+0 \quad 9.2 E+0 \quad 9.5 E+09.8 E+0 \quad 1.0 E+11.0 E+1$ $22 \quad 4.4 E+0 \quad 6.1 E+0 \quad 7.5 E+0 \quad 8.3 E+0 \quad 8.8 E+0 \quad 9.2 E+0 \quad 9.6 E+09.9 E+0 \quad 1.0 E+1 \quad 1.1 E+1 \quad 1.1 E+1 \quad 1.1 E+1$

\section{$P e_{M}=8.38$ (Average Error 7.15\%, Std. dev. of error $2.05 \%$ )}

$\begin{array}{lllllllllllll}\lambda_{a} \backslash \lambda_{c} & 0 & 2 & 4 & 6 & 8 & 10 & 12 & 14 & 16 & 18 & 20 & 22\end{array}$

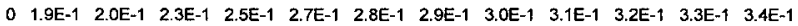

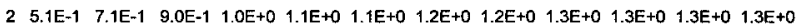

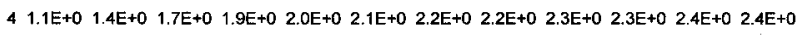

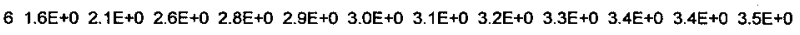

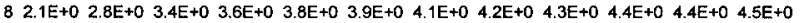
$102.7 E+0 \quad 3.5 E+0 \quad 4.1 E+0 \quad 4.5 E+0 \quad 4.7 E+0 \quad 4.8 E+0 \quad 5.0 E+0 \quad 5.1 E+0 \quad 5.2 E+05.3 E+0 \quad 5.4 E+05.5 E+0$ $123.2 \mathrm{E}+0 \quad 4.2 \mathrm{E}+0 \quad 4.9 \mathrm{E}+0 \quad 5.3 \mathrm{E}+0 \quad 5.5 \mathrm{E}+0 \quad 5.7 \mathrm{E}+0 \quad 5.9 \mathrm{E}+0 \quad 6.0 \mathrm{E}+0 \quad 6.2 \mathrm{E}+0 \quad 6.3 \mathrm{E}+0 \quad 6.4 \mathrm{E}+0 \quad 6.5 \mathrm{E}+0$ $143.7 \mathrm{E}+0 \quad 4.8 \mathrm{E}+0 \quad 5.7 \mathrm{E}+0 \quad 6.1 \mathrm{E}+0 \quad 6.3 \mathrm{E}+0 \quad 6.6 \mathrm{E}+0 \quad 6.7 \mathrm{E}+0 \quad 6.9 \mathrm{E}+0 \quad 7.1 \mathrm{E}+0 \quad 7.2 \mathrm{E}+0 \quad 7.3 \mathrm{E}+0 \quad 7.4 \mathrm{E}+0$ $16 \quad 4.2 \mathrm{E}+0 \quad 5.5 \mathrm{EE}+0 \quad 6.4 \mathrm{E}+0 \quad 6.9 \mathrm{E}+0 \quad 7.2 \mathrm{E}+0 \quad 7.4 \mathrm{E}+0 \quad 7.6 \mathrm{E}+0 \quad 7.8 \mathrm{E}+0$ 7.9E+0 $8.1 \mathrm{E}+0 \quad 8.2 \mathrm{E}+0 \quad 8.3 \mathrm{E}+0$ $18 \quad 4.8 E+0 \quad 6.1 E+0 \quad 7.1 E+0 \quad 7.6 E+0 \quad 8.0 E+0 \quad 8.2 E+0 \quad 8.4 E+0 \quad 8.6 E+0 \quad 8.8 E+0 \quad 9.0 E+0 \quad 9.1 E+09.2 E+0$ $20 \quad 5.4 E+0 \quad 6.8 E+0 \quad 7.9 E+0 \quad 8.4 E+0 \quad 8.8 E+0 \quad 9.0 E+0 \quad 9.3 E+0 \quad 9.5 E+0 \quad 9.7 E+0 \quad 9.8 E+0 \quad 1.0 E+1 \quad 1.0 E+1$

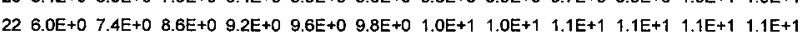

$P e_{M}=10.78$ (Average Error 8.6\%, Std. dev. of error $2.5 \%$ )

$\begin{array}{cccccccccccccr}\lambda_{a} \backslash \lambda_{c} & 0 & 2 & 4 & 6 & 8 & 10 & 12 & 14 & 16 & 18 & 20 & 22 \\ & 0 & 1.9 E-1 & 1.9 E-1 & 2.2 E-1 & 2.4 E-1 & 2.5 E-1 & 2.6 E-1 & 2.6 E-1 & 2.7 E-1 & 2.8 E-1 & 2.8 E-1 & 2.9 E-1 & 2.9 E-1\end{array}$

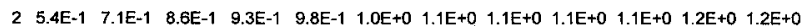

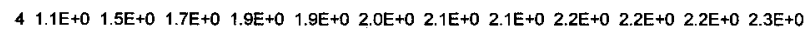

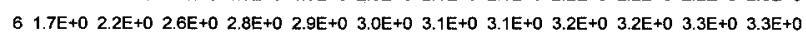
$82.3 E+0 \quad 3.0 E+0 \quad 3.4 E+0 \quad 3.7 E+0 \quad 3.8 E+0 \quad 3.9 E+0 \quad 4.0 E+0 \quad 4.1 E+0 \quad 4.2 E+0 \quad 4.2 E+0 \quad 4.3 E+0 \quad 4.4 E+0$ $10 \quad 3.0 E+0 \quad 3.7 E+0 \quad 4.3 E+0 \quad 4.5 E+0 \quad 4.7 E+0 \quad 4.8 E+0 \quad 5.0 E+0 \quad 5.1 E+0 \quad 5.1 E+0 \quad 5.2 E+0 \quad 5.3 E+0 \quad 5.4 E+0$ $123.5 E+0 \quad 4.4 E+0 \quad 5.1 E+05.4 E+0 \quad 5.6 E+0 \quad 5.7 E+0 \quad 5.9 E+0 \quad 6.0 E+0 \quad 6.1 E+0 \quad 6.2 E+0 \quad 6.3 E+06.3 E+0$ $14.1 .1 \mathrm{E}+0 \quad 5.2 \mathrm{E}+0 \quad 5.9 \mathrm{E}+0 \quad 6.2 \mathrm{E}+0 \quad 6.4 \mathrm{E}+0 \quad 6.6 \mathrm{E}+0 \quad 6.8 \mathrm{E}+0 \quad 6.9 \mathrm{E}+0 \quad 7.0 \mathrm{E}+0 \quad 7.1 \mathrm{E}+0 \quad 7.2 \mathrm{E}+0 \quad 7.3 \mathrm{E}+0$

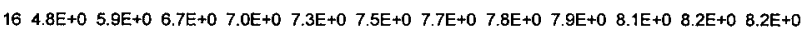
$18 \quad 5.4 E+0 \quad 6.6 E+0 \quad 7.4 E+0 \quad 7.9 E+0 \quad 8.1 E+0 \quad 8.4 E+0 \quad 8.5 E+0 \quad 8.7 E+0 \quad 8.8 E+0 \quad 9.0 E+0 \quad 9.1 E+09.2 E+0$ $20 \quad 6.0 E+0 \quad 7.3 E+0 \quad 8.2 E+0 \quad 8.7 E+0 \quad 9.0 E+0 \quad 9.2 E+09.4 E+0 \quad 9.6 E+0 \quad 9.7 E+0 \quad 9.9 E+0 \quad 1.0 E+11.0 E+1$

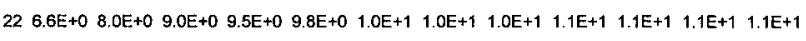

\section{$P e_{M}=13.74$ (Average Error 9.9\%, Std. dev. of error $2.9 \%$ )}

$\begin{array}{lllllllllllll}\lambda_{a} \backslash \lambda_{c} & 0 & 2 & 4 & 6 & 8 & 10 & 12 & 14 & 16 & 18 & 20 & 22\end{array}$ $\begin{array}{lllllllllllllllll}0 & 1.9 E-1 & 1.9 E-1 & 2.1 E-1 & 2.2 E-1 & 2.3 E-1 & 2.4 E-1 & 2.4 E-1 & 2.5 E-1 & 2.5 E-1 & 2.5 E-1 & 2.6 E-1 & 2.6 E-1\end{array}$

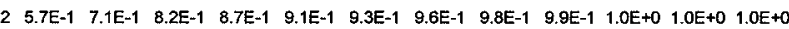

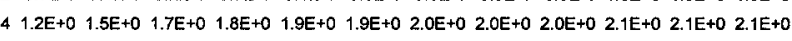
$6 \quad 1.9 E+0 \quad 2.3 E+0 \quad 2.6 E+0 \quad 2.8 E+0 \quad 2.9 E+0 \quad 2.9 E+0 \quad 3.0 E+0 \quad 3.0 E+0 \quad 3.1 E+0 \quad 3.1 E+0 \quad 3.2 E+0 \quad 3.2 E+0$ 8 2. $2.6 E+0 \quad 3.1 E+0 \quad 3.5 E+0 \quad 3.7 E+0 \quad 3.8 E+0 \quad 3.9 E+0 \quad 4.0 E+0 \quad 4.0 E+0 \quad 4.1 E+0 \quad 4.1 E+0 \quad 4.2 E+0 \quad 4.2 E+0$ $10 \quad 3.2 E+0 \quad 3.9 E+0 \quad 4.4 E+0 \quad 4.6 E+0 \quad 4.7 E+0 \quad 4.8 E+0 \quad 4.9 E+0 \quad 5.0 E+0 \quad 5.1 E+0 \quad 5.1 E+0 \quad 5.2 E+0 \quad 5.2 E+0$ $124.0 E+04.7 E+05.2 E+05.5 E+0 \quad 5.6 E+0 \quad 5.8 E+05.9 E+0 \quad 6.0 E+06.0 E+06.1 E+06.2 E+0 \quad 6.2 E+0$ $14.7 \mathrm{TE}+0 \quad 5.5 \mathrm{E}+0 \quad 6.1 \mathrm{EE}+0 \quad 6.4 \mathrm{E}+0 \quad 6.6 \mathrm{E}+0 \quad 6.7 \mathrm{E}+0 \quad 6.8 \mathrm{E}+0 \quad 6.9 \mathrm{E}+0 \quad 7.0 \mathrm{E}+0 \quad 7.1 \mathrm{E}+0 \quad 7.1 \mathrm{E}+0 \quad 7.2 \mathrm{E}+0$ $16 \quad 5.3 E+0 \quad 6.3 E+0 \quad 6.9 E+0 \quad 7.2 E+0 \quad 7.4 E+0 \quad 7.6 E+0 \quad 7.7 E+0 \quad 7.8 E+0 \quad 7.9 E+0 \quad 8.0 E+0 \quad 8.1 E+0 \quad 8.2 E+0$ $18 \quad 6.0 \mathrm{E}+0 \quad 7.0 \mathrm{EE}+0 \quad 7.8 \mathrm{E}+0 \quad 8.1 \mathrm{E}+0 \quad 8.3 \mathrm{E}+0 \quad 8.5 \mathrm{E}+0 \quad 8.6 \mathrm{E}+0 \quad 8.8 \mathrm{EE}+0 \quad 8.9 \mathrm{EE}+0 \quad 9.0 \mathrm{E}+0 \quad 9.1 \mathrm{E}+0 \quad 9.1 \mathrm{E}+0$ $206.7 \mathrm{E}+0 \quad 7.8 \mathrm{E}+0 \quad 8.6 \mathrm{E}+0 \quad 9.0 \mathrm{E}+0 \quad 9.2 \mathrm{E}+0 \quad 9.4 \mathrm{E}+0 \quad 9.5 \mathrm{E}+0 \quad 9.7 \mathrm{E}+0 \quad 9.8 \mathrm{E}+0 \quad 9.9 \mathrm{E}+0 \quad 1.0 \mathrm{E}+1 \quad 1.0 \mathrm{EE}+1$

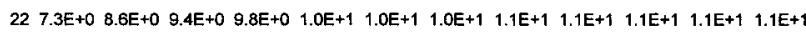

\section{$P e_{M}=16.5$ (Average Error $10.38 \%$, Std. dev. of error 3.02\%)}

$\begin{array}{lllllllllllll}\lambda_{a} \backslash \lambda_{c} & 0 & 2 & 4 & 6 & 8 & 10 & 12 & 14 & 16 & 18 & 20 & 22\end{array}$

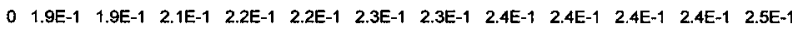
2 5.9E-1 7.1E-1 8.0E-1 8.4E-1 8.7E-1 8.9E-1 9.1E-1 9.2E-1 9.4E-1 9.5E-1 9.6E-1 9.7E-1

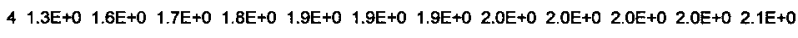

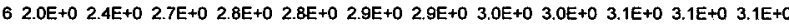

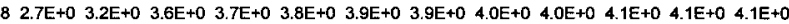
$10 \quad 3.4 E+0 \quad 4.0 E+0 \quad 4.5 E+0 \quad 4.6 E+0 \quad 4.7 E+0 \quad 4.8 E+0 \quad 4.9 E+0 \quad 5.0 E+0 \quad 5.0 E+0 \quad 5.1 E+0 \quad 5.1 E+0 \quad 5.2 E+0$ $124.2 \mathrm{E}+0 \quad 4.9 \mathrm{E}+0 \quad 5.3 \mathrm{E}+0 \quad 5.5 \mathrm{E}+0 \quad 5.7 \mathrm{E}+0 \quad 5.8 \mathrm{E}+0 \quad 5.9 \mathrm{E}+0 \quad 5.9 \mathrm{E}+0 \quad 6.0 \mathrm{E}+0 \quad 6.1 \mathrm{E}+0 \quad 6.1 \mathrm{E}+0 \quad 6.2 \mathrm{E}+0$

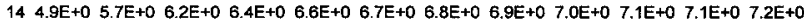
$165.6 \mathrm{E}+0 \quad 6.5 \mathrm{E}+0 \quad 7.1 \mathrm{E}+0 \quad 7.3 \mathrm{E}+0 \quad 7.5 \mathrm{E}+0 \quad 7.6 \mathrm{E}+0 \quad 7.8 \mathrm{E}+0 \quad 7.8 \mathrm{E}+0 \quad 7.9 \mathrm{E}+0 \quad 8.0 \mathrm{E}+0 \quad 8.1 \mathrm{E}+0 \quad 8.1 \mathrm{E}+0$ $18 \quad 6.4 E+0 \quad 7.3 E+0 \quad 7.9 E+0 \quad 8.2 E+0 \quad 8.4 E+0 \quad 8.6 E+0 \quad 8.7 E+0 \quad 8.8 E+0 \quad 8.9 E+0 \quad 9.0 E+0 \quad 9.0 E+09.1 E+0$ $207.0 \mathrm{E}+0 \quad 8.1 \mathrm{E}+0 \quad 8.8 \mathrm{E}+0$ 9.1E+0 $9.3 \mathrm{E}+0 \quad 9.5 \mathrm{E}+0 \quad 9.6 \mathrm{E}+0 \quad 9.7 \mathrm{E}+0 \quad 9.8 \mathrm{E}+0 \quad 9.9 \mathrm{E}+0 \quad 1.0 \mathrm{E}+1 \quad 1.0 \mathrm{E}+1$

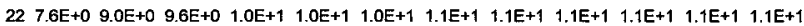

\section{$P e_{M}=19.7$ (Average Error 11\%, Std. dev. of error 3.1\%)}

$\begin{array}{llccccccccccr}\lambda_{a} \backslash \lambda_{c} & 0 & 2 & 4 & 6 & 8 & 10 & 12 & 14 & 16 & 18 & 20 & 22\end{array}$ 2 6.0E-1 7.1E-1 7.8E-1 8.1E-1 8.4E-1 8.5E-1 8.7E-1 8.8E-1 8.9E-1 9.0E-1 9.1E-1 9.1E-1

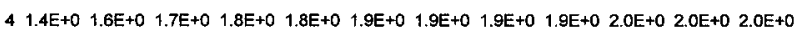

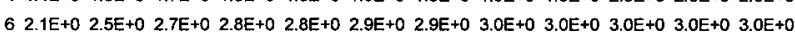
$8 \quad 2.9 E+0 \quad 3.3 E+0 \quad 3.6 E+0 \quad 3.7 E+0 \quad 3.8 E+0 \quad 3.9 E+0 \quad 3.9 E+0 \quad 4.0 E+0 \quad 4.0 E+0 \quad 4.0 E+0 \quad 4.1 E+0 \quad 4.1 E+0$ $10 \quad 3.7 E+0 \quad 4.2 E+0 \quad 4.5 E+0 \quad 4.7 E+0 \quad 4.8 E+0 \quad 4.8 E+0 \quad 4.9 E+0 \quad 5.0 E+0 \quad 5.0 E+0 \quad 5.0 E+0 \quad 5.1 E+0 \quad 5.1 E+0$ $12 \quad 4.4 E+0 \quad 5.0 E+0 \quad 5.4 E+0 \quad 5.6 E+0 \quad 5.7 E+0 \quad 5.8 E+0 \quad 5.9 E+0 \quad 5.9 E+0 \quad 6.0 E+0 \quad 6.0 E+0 \quad 6.1 E+0 \quad 6.1 E+0$ $145.2 \mathrm{E}+0 \quad 5.9 \mathrm{E}+0 \quad 6.3 \mathrm{E}+0 \quad 6.5 \mathrm{E}+0 \quad 6.7 \mathrm{E}+0 \quad 6.7 \mathrm{E}+0 \quad 6.8 \mathrm{E}+0 \quad 6.9 \mathrm{E}+0 \quad 7.0 \mathrm{E}+0 \quad 7.0 \mathrm{E}+0 \quad 7.1 \mathrm{E}+0 \quad 7.1 \mathrm{E}+0$ $165.9 \mathrm{E}+0 \quad 6.7 \mathrm{E}+0 \quad 7.2 \mathrm{E}+0 \quad 7.4 \mathrm{E}+0 \quad 7.6 \mathrm{E}+0 \quad 7.7 \mathrm{E}+0 \quad 7.8 \mathrm{E}+0 \quad 7.9 \mathrm{E}+0 \quad 7.9 \mathrm{EE}+0 \quad 8.0 \mathrm{E}+0 \quad 8.1 \mathrm{E}+0.0 .1 \mathrm{E}+0$ $18 \quad 6.6 \mathrm{E}+0 \quad 7.6 \mathrm{E}+0 \quad 8.1 \mathrm{E}+0 \quad 8.3 \mathrm{E}+0 \quad 8.5 \mathrm{E}+0 \quad 8.6 \mathrm{E}+0 \quad 8.7 \mathrm{E}+0 \quad 8.8 \mathrm{E}+0 \quad 8.9 \mathrm{E}+0 \quad 9.0 \mathrm{E}+0 \quad 9.0 \mathrm{EE}+0 \quad 9.1 \mathrm{E}+0$ $207.3 E+0 \quad 8.4 E+0 \quad 9.0 E+0 \quad 9.2 E+0 \quad 9.4 E+0 \quad 9.6 E+0 \quad 9.7 E+0 \quad 9.8 E+09.9 E+0 \quad 9.9 E+0 \quad 1.0 E+1 \quad 1.0 E+1$

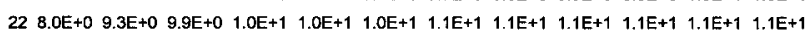




$$
\left\langle\sigma_{\mathrm{m}}^{*}\right\rangle=\frac{\left\langle\sigma_{\mathrm{m}}\right\rangle}{\sigma_{\mathrm{T}}}=1 / \int_{0}^{1} \frac{d x^{*}}{\sigma_{\lambda}}
$$

where $\sigma_{\mathrm{T}}$ is the temperature-dependent part of the electrical conductivity, while $\sigma_{\lambda}$ is the concentration-dependent part, such that $\sigma_{\mathrm{m}}$ $=\sigma_{\mathrm{T}} \sigma_{\lambda}$. Because $\lambda=\lambda\left(x^{*}, P e_{\mathrm{M}}, \lambda_{\mathrm{a}}, \lambda_{\mathrm{c}}\right)$ and $\sigma_{\mathrm{m}}=\sigma_{\mathrm{m}}(\lambda, T)$, it follows that $\sigma_{\mathrm{m}}^{*}=\sigma_{\mathrm{m}} / \sigma_{\mathrm{T}}=\sigma_{\mathrm{m}}^{*}\left(x^{*}, P e_{\mathrm{M}}, \lambda_{\mathrm{a}}, \lambda_{\mathrm{c}}\right)$. Integration over $x^{*}$ results in $\left\langle\sigma_{\mathrm{m}}^{*}\right\rangle=\left\langle\sigma_{\mathrm{m}}^{*}\right\rangle\left(P e_{\mathrm{M}}, \lambda_{\mathrm{a}}, \lambda_{\mathrm{c}}\right)$, which implies that a threedimensional table with the same parametric space as needed to store the water flux across the membrane, is also adequate to store the average conductivity of the membrane.

The nondimensional water flux and the nondimensional average electrical conductivity are tabulated in Tables III and IV, respectively. These two tables represent the data that are necessary for coupling the convection-extended generalized form of the Springer model to large-scale CFD calculations. For negative $P e_{\mathrm{M}}$, the corresponding positive $P e_{\mathrm{M}}$ data should be used with the $\left[\lambda_{\mathrm{a}}, \lambda_{\mathrm{c}}\right]$ pair reversed. This can easily be proved using a coordinate transformation for Eq. 23.

One critical issue in the use of such lookup tables is the errors associated with interpolation. In order to address this issue, a rigorous error analysis was performed to quantify errors due to interpolation in both the water flux as well as the conductivity. The average errors and their standard deviations are also shown in Tables III and IV. The error was computed for odd values of $\left[\lambda_{a}, \lambda_{c}\right]$, which do not appear directly in the tables, and have to be obtained by interpolation during use of the tables. The error is defined as

$$
\% \text { Error }=\left|\frac{\text { Computed value }- \text { Value obtained by interpolation }}{\text { Computed value }}\right|
$$$$
\times 100
$$

It is seen that the average error in either the water flux or the electrical conductivity never exceeds $11 \%$. If a $\pm 3 \sigma$ deviation from the average is considered, the maximum errors in the water flux is about $15 \%$, while the maximum error in the electrical conductivity is about $20 \%$. This includes interpolation between two different Peclet numbers. In light of the numerical errors shown in Table I for just a single isolated case (the maximum values are expected to be much larger than the values shown for this single case, chosen at random), it is clear that using the lookup table would provide better accuracy than performing direct calculations with a few tens of grid points across the membrane, not to mention the drastic improvement in computational efficiency.

\section{Conclusions}

A phenomenological model based upon the semiempirical model of Springer et al. ${ }^{39}$ has been presented. Convective transport of water has been added to the original model in an attempt to mimic Schroeder's paradox, although as discussed earlier, this can only be done comprehensively if a full-blown two-phase formulation in which both liquid and vapor fractions of water are tracked is used. The resulting convection-drift-diffusion equation was solved using a conservative finite-volume approach. It is shown that significant grid refinement is necessary to accurately calculate the net water flux across the membrane, and that the assumption of a linear water profile within the membrane leads to very large errors in cases where the diffusion and electro-osmotic drag are in opposite directions. The conclusion is that CFD calculations with a few grid points within the membrane are likely to produce erroneous results. One possible solution to this problem is to generate an off-line database that can be coupled to large-scale calculations. In this article, the computed results of this model have been tabulated in nondimensional form. This database will allow accurate calculation of water transport and current transport within the membrane and can be used within the framework of large-scale CFD calculations without sacrificing either accuracy or efficiency.

\section{Acknowledgments}

The author thanks an anonymous reviewer for helpful comments.

The Ohio State University assisted in meeting the publication costs of this article.

\section{List of Symbols}

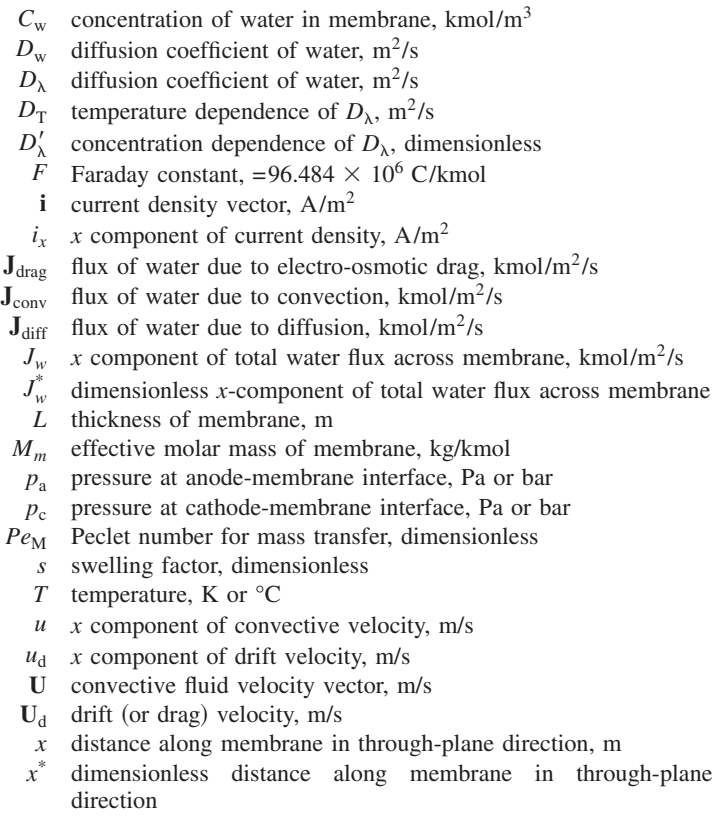

Greek

$\eta_{\mathrm{d}}$ electro-osmotic drag coefficient, dimensionless

$\mu$ dynamic viscosity of liquid water, $\mathrm{kg} / \mathrm{m} / \mathrm{s}$

$\kappa$ hydraulic permeability of liquid water, $\mathrm{m}^{2}$

$\lambda$ water content, dimensionless

$\lambda_{a}$ water content at anode-membrane interface, dimensionless

$\lambda_{\mathrm{c}}$ water content at cathode-membrane interface, dimensionles

$\phi_{\text {ma }}$ membrane phase potential at anode-membrane interface, $\mathrm{V}$

$\phi_{\mathrm{mc}}$ membrane phase potential at cathode-membrane interface, $\mathrm{V}$

$\rho_{\mathrm{m}} \quad$ density of wet membrane, $\mathrm{kg} / \mathrm{m}^{3}$

$\rho_{\mathrm{m}}^{\text {dry }}$ density of dry membrane, $\mathrm{kg} / \mathrm{m}^{3}$

$\sigma_{\mathrm{m}}$ ionic conductivity of membrane, $\Omega^{-1} \mathrm{~m}^{-1}$

$\sigma_{\mathrm{T}}$ temperature dependent part of $\sigma_{\mathrm{m}}, \Omega^{-1} \mathrm{~m}^{-1}$

$\sigma_{\lambda}$ concentration dependent part of $\sigma_{\mathrm{m}}, \Omega^{-1} \mathrm{~m}^{-1}$

$\left\langle\sigma_{\mathrm{m}}\right\rangle$ average ionic (or electrical) conductivity of membrane, $\Omega^{-1} \mathrm{~m}^{-1}$

$\left\langle\sigma_{\mathrm{m}}^{*}\right\rangle$ dimensionless average ionic (or electrical) conductivity of membrane

\section{References}

1. V. Gurau, H. Liu, and S. Kakac, AIChE J., 44, 2410 (1998)

2. D. Singh and N. Djilali, Int. J. Eng. Sci., 37, 431 (1999).

3. S. Um, C.-Y. Wang, and K. Chen, J. Electrochem. Soc., 147, 4485 (2000).

4. D. Natarajan and T. Nguyen, J. Electrochem. Soc., 148, A1324 (2001).

5. N. Siegel, M. Ellis, D. Nelson, and M. Von Spakovsky, J. Power Sources, 128, 173 (2004).

6. S. Mazumder and V. Cole, J. Electrochem. Soc., 150, A1503 (2003)

7. S. Mazumder and V. Cole, J. Electrochem. Soc., 150, A1510 (2003).

8. S. Dutta, S. Shimpalee, and J. Van Zee, J. Electroanal. Chem., 330, 135 (2000).

9. S. Dutta, S. Shimpalee, and J. Van Zee, Int. J. Heat Mass Transfer, 44, 2029 (2001)

10. S. Um and C.-Y. Wang, in Proceedings of the ASME Fuel Cell Division, ASME IMechE, Orlando, FL (2000).

11. T. Berning, D. M. Lu, and N. Djilali, J. Power Sources, 106, 284 (2002).

12. W.-K. Lee, S. Shimpalee, and J. Van Zee, J. Electrochem. Soc., 150, A341 (2003)

13. S. Eldrid, M. Shahnam, M. Prinkey, and Z. Dong, Proceedings of the Annual ASME Fuel Cell Conference, Paper 2003-1719, p. 195 (2003).

14. A. Kulikovsky, J. Electrochem. Soc., 150, A1432 (2003)

15. T. Berning and N. Djilali, J. Electrochem. Soc., 150, A1589 (2003).

16. P. C. Sui and N. Djilali, in Proceedings of the International Fuel Cell Science, Engineering and Technology Conference, Rochester, NY, ASME FUEL CELL 2004-2444, pp. 7-14 (2004).

17. D. Natarajan and T. Nguyen, J. Power Sources, 115, 66 (2003).

18. P.-W. Li, L. Schaefer, Q.-M. Wang, T. Zhang, and M. K. Chyu, J. Power Sources, $115,90(2003)$. 
19. A. Kumar and R. Reddy, J. Power Sources, 113, 11 (2003a).

20. P. Nguyen, T. Berning, and N. Djilali, J. Power Sources, 130, 149 (2004).

21. S. Um and C.-Y. Wang, J. Power Sources, 125, 40 (2004).

22. S. Paddison, R. Paul, and T. Zawodzinski, J. Electrochem. Soc., 147, 617 (2000).

23. P. Khalatur, S. Talitskikh, and A. Khokhlov, Macromol. Theory Simul., 11, 566 (2002).

24. D. Mologin, P. Khalatur, and A. Khokhlov, Macromol. Theory Simul., 11, 587 (2002).

25. R. Jinnouchi, Microscale Thermophys. Eng., 7, 15 (2003).

26. T. Nguyen and R. White, J. Electrochem. Soc., 140, 2178 (1993).

27. T. Fuller and J. Newman, J. Electrochem. Soc., 140, 1211 (1993).

28. T. Thampan, S. Malhotra, H. Tang, and R. Datta, J. Electrochem. Soc., 147, 3242 (2000).

29. F. Buchi and G. Scherer, J. Electrochem. Soc., 148, A183 (2001).

30. G. Janssen, J. Electrochem. Soc., 148, A1313 (2001).

31. G. Janssen and M. Overvelde, J. Power Sources, 101, 117 (2001).

32. A. Kulikovsky, J. Electrochem. Soc., 150, A1432 (2003).

33. A. Weber and J. Newman, J. Electrochem. Soc., 150, A1008 (2003).

34. M. De Francesco, E. Arato, and P. Costa, J. Power Sources, 132, 127 (2004).

35. W.-M. Yan, F. Chen, H.-Y. Wu, C.-Y. Soong, and H.-S. Chu, J. Power Sources, 129, 127 (2004).
36. A. Weber and J. Newman, J. Electrochem. Soc., 151, A311 (2004).

37. A. Weber and J. Newman, J. Electrochem. Soc., 151, A326 (2004).

38. P. Berg, K. Promislow, J. St. Pierre, J. Stumper, and B. Wetton, J. Electrochem. Soc., 151, A341 (2004).

39. T. E. Springer, T. A. Zawodzinski, and S. Gottesfeld, J. Electrochem. Soc., 138 $2334(1991)$

40. A. Weber and J. Newman, Chem. Rev. (Washington, D.C.), 104, 4679 (2004).

41. D. Bernardi and M. Verbrugge, AIChE J., 37, 1151 (1991).

42. D. Bernardi and M. Verbrugge, J. Electrochem. Soc., 139, 2477 (1992).

43. C.-Y. Wang, Chem. Rev. (Washington, D.C.), 104, 4727 (2004).

44. P. Choi and R. Datta, J. Electrochem. Soc., 150, E601 (2003).

45. P. Costamagna, Chem. Eng. Sci., 56, 323 (2001).

46. A. Rowe and X. Li, J. Power Sources, 102, 82 (2001).

47. J. Ferziger and M. Peric, Computational Methods for Fluid Dynamics, Chap. 4, 2nd ed., Springer Verlag (1999).

48. R. Bird, W. Stewart, and E. Lightfoot, Transport Phenomena, John Wiley and Sons, New York (1960).

49. P. Kundu, Fluid Mechanics, Academic Press Inc., New York (1990).

50. D. Genevey, M.S. Thesis, Virginia Polytechnic Institute and State University Blacksburg, VA (2001). 